\title{
Life-Cycle Seismic Fragility Assessment of Existing RC Bridges Subject to Chloride-Induced Corrosion in Marine Environment
}

\author{
Sicong Hu $\mathbb{D}^{\text {, }}$, Zheyan Wang, Yu Guo, and Gui Xiao \\ School of Civil Engineering and Architecture, Nanchang University, Nanchang, China \\ Correspondence should be addressed to Sicong Hu; eric731hu@ncu.edu.cn
}

Received 7 April 2021; Accepted 19 May 2021; Published 14 June 2021

Academic Editor: Haoyuan Hong

Copyright (c) 2021 Sicong Hu et al. This is an open access article distributed under the Creative Commons Attribution License, which permits unrestricted use, distribution, and reproduction in any medium, provided the original work is properly cited.

\begin{abstract}
Bridges in a marine environment have been suffering from the chloride attack for a long period of time. Due to the fact that different sections of piers may be exposed to different conditionals, the chloride-induced corrosion not only affects the scale of the deterioration process but also significantly modifies over time the damage propagation mechanisms and the seismic damage distribution. In order to investigate the seismic damage of existing RC bridges subject to spatial chloride-induced corrosion in a marine environment, Duracrete model is applied to determine the corrosion initiation time of reinforcing steels under different exposure conditionals and the degradation models of reinforcing steels, confined concrete, and unconfined concrete are obtained based on the previous investigation. According to the seismic fragility assessment method, the damage assessment approach for the existing RC bridges subject to spatial chloride-induced corrosion in a marine environment is present. Moreover, a case study of a bridge under two kinds of water regions investigated the influence of spatial chloride-induced corrosion on the seismic damage of piers and other components. The results show that the spatial chloride-induced corrosion may result in the section at the low water level becoming more vulnerable than the adjacent sections and the alteration of seismic damage distribution of piers. The corrosion of pier will increase the seismic damage probability of itself, whereas it will result in a reduction of seismic damage probability of other components. Moreover, the alteration of seismic damage distribution of piers will amplify the effect. Due to the fact that the spatial chloride-induced corrosion of piers may alter the yield sequence of cross section, it then affects the seismic performance assessment of piers. A method to determine the evolution probability of yield sequence of corroded piers is proposed at last. From the result, the evolution probability of yield sequence of piers in longitudinal direction depends on the relationship between the height of piers and submerged zone. Moreover, the height of piers, submerged zone, and tidal zone have a common influence on the evolution of yield sequence of piers in transversal direction.
\end{abstract}

\section{Introduction}

In the past decades, many coastal bridges have been built in different countries with long coastlines to meet the growing requirement of fast transport and economic development. Overall, most of these bridges are reinforced concrete structures and are located in the severe marine environments. Under such environments, chloride-induced corrosion is a major environmental stressor for RC bridges, because it may result in the decrease of the effective crosssectional area of the reinforcing steels and the deterioration of the mechanical properties of reinforcing steels and concrete. Obviously, the performance of coastal bridges is expected to be significantly affected by chloride-induced corrosion. Therefore, it is of interest to investigate the effects of chloride-induced corrosion on the performance of aging $\mathrm{RC}$ bridges in marine environments and to improve the performance level of these bridges with the corrosion effects.

On the other hand, chloride-induced corrosion may also result in the decrease of the seismic performance of aging RC bridges; thereby bridges exhibit different seismic damage probability as time increases. In this respect, many studies have focused on the seismic damage assessment of RC bridges with chloride-induced corrosion. Choe et al. [1] developed the probabilistic drift and shear force capacity models for corroding reinforced concrete columns to predict the service-life and life-cycle cost of the columns. Kumar et al. [2] assessed the seismic damage probability of the aging bridges with the cumulative seismic damage and chlorideinduced corrosion. Alipour et al. [3] investigated the effects 
of reinforcement corrosion on the seismic damage probability of the aging bridge in California with different structural parameters. Thanapol et al. [4] developed the seismic fragility curves of the deteriorating piers through the field instrumentation of the corrosion measurements. Cui et al. [5] applied an improved deterioration model of the reinforced concrete steel to carry out the seismic fragility analysis of the reinforced concrete bridges with the marine chloride-induced corrosion. Panchireddi and Ghosh [6] proposed an analytical strategy to consider the deterioration of the damaged bridge through updating the pier section properties. Zhang et al. [7] proposed a seismic risk assessment method for the corrosion RC bridges with shearcritical columns. Crespi [8] presented a procedure for the collapse mechanism evaluation of the existing reinforced concrete motorway bridges under horizontal loads.

Overall, the previous studies have enriched the knowledge of the seismic damage assessment of aging RC bridges. However, only uniform exposure condition was considered in these studies when performing the seismic damage assessment of aging RC bridges with the corrosion effects. In fact, exposure conditions exhibit significant spatial variation characteristic along the pier direction for many coastal bridges, and the nonuniform degradation phenomenon occurs in the corroded piers, resulting in the nonuniform distribution of seismic damage of piers. Obviously, these studies may be inappropriate and/or inadequate to completely investigate probabilistic seismic damage of aging RC bridges and to reveal the effects of spatial chloride-induced corrosion. On the other hand, the knowledge of plastic hinges of piers will contribute to the ductile seismic design of RC bridges. Recently, Yuan et al. [9] investigated the damage characteristics of the coastal bridge piers suffering nonuniform corrosion by the shaking table tests. However, the yield characteristic of piers subject to the spatial chlorideinduced corrosion has not been comprehensively investigated in the previous studies, and the evolution mechanism of yield sequence of corroded piers has not been clarified.

In this study, the probabilistic seismic damage assessment of aging RC bridges subject to spatial chloride-induced corrosion in marine environments is presented. Overall, the major objectives of this study are threefold: (1) to develop a probabilistic seismic damage assessment procedure for aging RC bridges suffering spatial chloride-induced corrosion, (2) to reveal the effects of spatial chloride-induced corrosion on the seismic damage characteristics of piers and other components, and (3) to discuss the evolution probability of yield sequence of piers subject to spatial chloride-induced corrosion. The paper is organized as follows: In Section 2, we describe the corrosion process of reinforcing steels and degradation properties of various materials under different marine exposure conditions. Section 3 presents the probabilistic seismic damage assessment procedure for aging RC bridges subject to spatial chloride-induced corrosion. Subsequently, details of the case study bridge are described in Section 4, and the finite element models are developed. In Section 5, the corrosion level and seismic capacity of RC piers in different exposure conditions are investigated. Moreover, the seismic damage of piers and other components is discussed in Section 6. Furthermore, a method to determine the evolution probability of yield sequence of piers subject to spatial chloride-induced corrosion is proposed in Section 7. A brief summary of the results is presented in Section 8 .

\section{Chloride-Induced Corrosion Effects}

The coastal bridges are often exposed to high concentrations of chloride ions. The concentration gradient between the exposed surface and the pore solution of the cement makes the chloride ions penetrate from the external environment through the concrete cover and reach the surface of reinforcing steels. Moreover, the chloride ions decrease the $\mathrm{pH}$ in the concrete and break down the passive film of reinforcing steels, resulting in the corrosion of reinforcing steels and the damage of concrete. In this section, the corrosion processes of reinforcing steels and the deterioration mechanism of RC members are presented.

2.1. Corrosion Initiation Time. The corrosion initiation time is an important parameter during the chloride-induced corrosion process of RC members, which can be defined as the time when the chloride ions concentration near reinforcing steels reaches a threshold concentration $C_{c r}$. To calculate the corrosion initiation time, it is necessary to describe the diffusion process of chloride ions and determine the chloride ions concentration at different depths of RC members. In this respect, Duracrete provided a probabilistic model to predict the chloride concentration in the concrete by taking into account the timedependent characteristics of chloride diffusion, as well as the different types of uncertainties associated with the modelling of these complex processes [10]. The chloride concentration at depth $x$ after time $t$ can be expressed as follows:

$$
C(x, t)=C_{c s}\left[1-\operatorname{erf}\left(\frac{x}{2 \sqrt{k_{e} k_{t} k_{c} D_{0}\left(t_{0}\right)^{n}(t)^{1-n}}}\right)\right],
$$

where $\operatorname{erf}(\theta)=(2 / \sqrt{\pi}) \int_{0}^{\theta} e^{-t^{2}} \mathrm{~d} t$ is the error function; $D_{0}$ is the empirical diffusion coefficient; $k_{e}$ is an environmental coefficient; $k_{t}$ represents the influence of test methods on determining $D_{0} ; k_{c}$ is a coefficient that accounts for the influence of curing; $t_{0}$ is the reference period for $D_{0} ; n$ is the age factor; $C_{c s}$ is the chloride concentration at concrete surface and can be represented as

$$
C_{c s}=A_{c s}\left(\frac{w}{b}\right)+\varepsilon_{c s},
$$

where $w / b$ is the water binder ratio and $A_{c s}$ and $\varepsilon_{c s}$ are the model parameters.

If the cover depth of reinforcing steels $d_{c}$ is known, the corrosion initiation time can be determined as follows:

$$
T_{\text {cor }}=\left\{\frac{d_{c}^{2}}{4 k_{e} k_{t} k_{c} D_{0}\left(t_{0}\right)^{n}}\left[\operatorname{erf}^{-1}\left(\frac{C_{c s}-C_{c r}}{C_{c s}}\right)\right]^{-2}\right\}^{(1 /(1-n))} .
$$

For many coastal bridges, the bottom of piers may be submerged in the water, whereas the middle and top of piers are exposed to chloride dry-wet cycle and atmosphere environment, respectively. The discrepancies of humidity, 
temperature, oxygen, and chloride concentration will cause the different corrosion initiation time of reinforcing steels in various marine exposure conditions. Therefore, the corrosion level of reinforcing steels is highly dependent on the type of exposure conditions. Overall, four categories of exposure conditions are included in the Duracrete model: (a) submerged zone, (b) tidal zone, (c) splash zone, and (d) atmospheric zone. Table 1 summarizes the statistical parameters for corrosion coefficients in the Duracrete model.

2.2. Corrosion Propagation. Generally, the corrosion form of reinforcing steels can be divided into two types: uniform corrosion and pitting corrosion (Figure 1). The former is caused by carbonation, whereas the latter is caused by chloride penetration [11]. Therefore, the pitting corrosion is considered during the corrosion analysis in this study.

The classical model proposed by $\mathrm{Val}$ and Melchers simplified the geometry of pitting into a quadrilateral form approximately to consider the reduction of reinforcement area [12]. The time-dependent residual cross-sectional area of a reinforcing steel with pitting corrosion $A_{\text {res }}(t)$ can be represented as follows:

$$
A_{\text {res }}(t)=\left[1-Q_{\text {cor }}(t)\right] A_{0}=\left[A_{0}-A_{\text {cor }, p}(t)\right],
$$

where $Q_{\text {cor }}(t)$ is the time-dependent percentage mass loss of corroded reinforcing steels; $A_{0}$ is the initial cross-sectional area of reinforcing steels; $A_{\text {cor }, p}(t)$ is the time-dependent pitting area of reinforcing steels and it can be calculated as follows:

$$
\begin{aligned}
A_{\text {cor }, p}(t) & = \begin{cases}A_{1}+A_{2}, & P(t) \leq \frac{d_{s 0}}{\sqrt{2}}, \\
\frac{\pi d_{s 0}^{2}}{4}-A_{1}+A_{2}, & \frac{d_{s 0}}{\sqrt{2}}<P(t) \leq d_{s 0}, \\
\frac{\pi d_{s 0}^{2}}{4}, & P(t) \geq d_{s 0},\end{cases} \\
A_{1}= & \frac{1}{2}\left[\theta_{1}\left(\frac{d_{s 0}}{2}\right)^{2}-\frac{b}{2} \sqrt{d_{s 0}^{2}-b^{2}}\right], \\
A_{2}= & \frac{1}{2}\left[\theta_{2} P(t)^{2}-\frac{b P(t)^{2}}{d_{s 0}}\right],
\end{aligned}
$$

$$
\begin{aligned}
\theta_{1} & =2 \arcsin \left(\frac{b}{d_{s 0}}\right), \\
\theta_{2} & =2 \arcsin \left(\frac{b}{2 P(t)}\right), \\
b & =2 P(t) \sqrt{1-\left(\frac{P(t)}{d_{s 0}}\right)^{2},}
\end{aligned}
$$

where $d_{s 0}$ is the initial diameter of reinforcing steels; $P(t)$ is the time-dependent pitting depth, and it can be expressed by

$$
P(t)=R \int_{T_{\text {cor }}}^{t} \lambda(t) \mathrm{d} t,
$$

where is $\lambda(t)$ is uniform corrosion rate; $R$ is pitting factor, which represents the ratio of maximum pit depth to average depth considering uniform corrosion.

A Gumbel (Extreme Value Type I) distribution can be applied to predict the pitting factor of reinforcing steels [13]. Consequently, the statistical parameters of $R$ can be calculated as

$$
\begin{aligned}
& \mu=\mu_{0}+\frac{1}{\alpha_{0}} \ln \left(\frac{A_{U}}{A_{0}}\right), \\
& \alpha=\alpha_{0},
\end{aligned}
$$

where $\mu_{0}$ and $\alpha_{0}$ are the scale and location parameters in the Gumbel distribution, respectively; $A_{0}$ is taken as the surface area of reinforcing steels with $125 \mathrm{~mm}$ length and $8 \mathrm{~mm}$ diameter; $A_{U}$ is the surface area of reinforcing steels with other sizes.

In theory, the uniform corrosion rate of reinforcing steels $\lambda(t)$ is related to the corrosion current density. The corrosion current density will reduce and approach a constant level with the development of corrosion. Moreover, the unconfined concrete cracking will lead to easier ingress of chlorides, oxygen, and water, entailing the corrosion rate of reinforcement undergoing a large continuous increase after crack initiation and subsequent crack growth $[14,15]$. To fully consider these effects, an improved time-dependent uniform corrosion rate model is proposed by Cui et al. [5] based on the $\mathrm{Vu}$ and Stewart model [16]:

$$
\begin{aligned}
& \lambda(t)= \begin{cases}\lambda^{\prime}(t), & T_{\text {cor }}<t<T_{c r}, \\
\frac{\left(t-T_{c r}\right)\left[4.5-26 \lambda^{\prime}\left(T_{W c r}\right)\right] \lambda^{\prime}\left(T_{W c r}\right)+\left(T_{W c r}-t\right) \lambda^{\prime}\left(T_{c r}\right)}{T_{W c r}-T_{c r}}, & T_{c r}<t<T_{W c r}, \\
{\left[4.5-26 \lambda^{\prime}(t)\right] \lambda^{\prime}(t),} & T_{W c r}<t,\end{cases} \\
& \lambda^{\prime}(t)=0.0116 \times 0.85 \times \frac{37.8(1-w / c)^{-1.64}}{d_{c}} \times\left(t-T_{c o r}\right)^{-0.29},
\end{aligned}
$$

where $w / c$ is the water cement ratio; $T_{c r}$ and $T_{W c r}$ are initial cracking time and initiation of severe cracking time, respectively. The detailed calculation method is illustrated in [5]. 
TABLE 1: Statistical parameters for corrosion coefficients in the Duracrete model.

\begin{tabular}{|c|c|c|c|c|c|c|c|c|c|}
\hline \multirow{2}{*}{ Parameter } & \multirow{2}{*}{ Distribution type } & \multicolumn{2}{|c|}{ Atmospheric } & \multicolumn{2}{|c|}{ Splash } & \multicolumn{2}{|c|}{ Tidal } & \multicolumn{2}{|c|}{ Submerged } \\
\hline & & Mean & Std. & Mean & Std. & Mean & Std. & Mean & Std. \\
\hline$D_{0}(w / b=0.4)$ & Normal & 220 & 25.4 & 220 & 25.4 & 220 & 25.4 & 220 & 25.4 \\
\hline$D_{0}(w / b=0.45)$ & Normal & 315.6 & 32.5 & 315.6 & 32.5 & 315.6 & 32.5 & 315.6 & 32.5 \\
\hline$D_{0}(w / b=0.5)$ & Normal & 473 & 43.2 & 473 & 43.2 & 473 & 43.2 & 473 & 43.2 \\
\hline$n$ & Beta $(A=0.0, B=0.98)$ & 0.362 & 0.245 & 0.362 & 0.245 & 0.362 & 0.245 & 0.362 & 0.245 \\
\hline$A_{c s}$ & Normal & 2.565 & 0.356 & 7.758 & 1.36 & 7.758 & 1.36 & 10.348 & 0.714 \\
\hline$\varepsilon_{c s}$ & Normal & 0 & 0.58 & 0 & 1.105 & 0 & 1.105 & 0 & 0.405 \\
\hline$C_{c r}$ & Normal & 0.9 & 0.15 & 0.9 & 0.15 & 0.9 & 0.15 & 1.6 & 0.2 \\
\hline$k_{t}$ & Normal & 0.832 & 0.024 & 0.832 & 0.024 & 0.832 & 0.024 & 0.832 & 0.024 \\
\hline$k_{e}$ & Gamma & 0.676 & 0.114 & 0.265 & 0.045 & 0.924 & 0.155 & 0.325 & 0.223 \\
\hline$k_{c}(t=1$ days $)$ & Beta $(A=1.0, B=4.0)$ & 2.4 & 0.7 & 2.4 & 0.7 & 2.4 & 0.7 & 2.4 & 0.7 \\
\hline$k_{c}(t=3$ days $)$ & Beta $(A=1.0, B=4.0)$ & 1.5 & 0.3 & 1.5 & 0.3 & 1.5 & 0.3 & 1.5 & 0.3 \\
\hline$k_{c}(t=7$ days $)$ & Determined value & 1 & - & 1 & - & 1 & - & 1 & - \\
\hline$k_{c}(t=28$ days $)$ & Beta $(A=0.4, B=1.0)$ & 0.8 & 0.1 & 0.8 & 0.1 & 0.8 & 0.1 & 0.8 & 0.1 \\
\hline
\end{tabular}

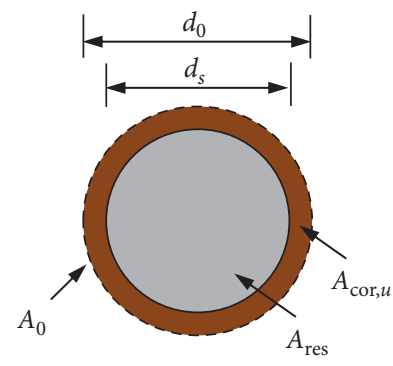

(a)

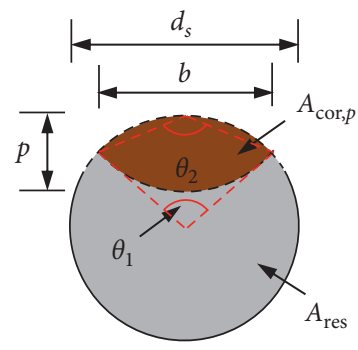

(b)

FIGURE 1: (a) Uniform corrosion and (b) pitting corrosion of reinforcing steels.

2.3. Material Properties. As stated, chloride-induced corrosion will affect the effective sectional area and mechanical properties of reinforcing steels. Moreover, the expansive pressure localized at the interface between reinforcing steels and concrete can also result in the cracking and spalling of concrete cover. At the same time, the deterioration of transverse reinforcement may reduce the lateral confinement of core concrete, resulting in the decrease of strength and ultimate strain of confined concrete. To fully consider the overall performance of corroded RC members, the degradation properties of reinforcing steels, concrete cover, and confined concrete should be determined.

2.3.1. Reinforcing Steels. Du et al. [17] proposed a linear strength reduction model as a function of the percentage mass loss $Q_{\text {cor }}$ of corroded reinforcing steels:

$$
f=\left[1-\beta Q_{\text {cor }}\right] f_{0} \text {, }
$$

where $f_{0}$ and $f$ are the strength of uncorroded and corroded reinforcing steels, respectively; $\beta$ is coefficient of strength degradation, which is taken as 0.49 for the yield strength and 0.65 for the ultimate strength.

2.3.2. Concrete Cover. The reduction in concrete cover strength $f_{c}$ can be calculated as follows [18]:

$$
f_{c}=\frac{f_{c 0}}{1+K \varepsilon_{1} / \varepsilon_{0}}
$$

where $f_{c 0}$ is the peak compressive strength of the undamaged concrete; $K$ is a coefficient related to the roughness and diameter of reinforcing steels, which can be 0.1 for medium diameter ribbed reinforcing steels [19]; $\varepsilon_{0}$ is the strain at peak stress in compression; $\varepsilon_{1}$ is the average tensile strain of cracked concrete perpendicular to the direction of stress, which can be calculated as follows:

$$
\varepsilon_{1}=\frac{n_{\mathrm{bars}} \kappa_{w}\left(\Delta A_{s}-\Delta A_{s 0}\right)}{b_{0}},
$$

where $b_{0}$ is the width of pristine cross section; $n_{\text {bars }}$ is the amount of longitudinal reinforcement in compressed regions; $\kappa_{w}$ is the empirical coefficient, which is taken as $0.0575 \mathrm{~mm}^{-1} ; \Delta A_{s}$ is the area loss of reinforcing steels; $\Delta A_{s 0}$ is the critical area loss of reinforcing steels for cracking initiation, which can be evaluated as [20]

$$
\Delta A_{s 0}=A_{s}-A_{s}\left[1-\frac{\delta\left(7.53+9.32 d_{c} / d_{s 0}\right)}{1000 d_{s 0}}\right]^{2},
$$

where $\delta$ is the pitting concentration factor, which is taken as 4 to $8 ; A_{s}$ is the area of pristine cross section. 
2.3.3. Confined Concrete. The Mander stress-strain relationship is utilized to simulate the behaviour of confined concrete after corrosion [21]. For a circular cross section, the confined strength $f_{\mathrm{cc}}^{\prime}$ and ultimate strain $\varepsilon_{c u}$ of core concrete are estimated as

$f_{\mathrm{cc}}^{\prime}=f_{c 0}\left(2.254 \times \sqrt{1+\frac{7.94 \times 0.5 K_{e} \rho_{h} f_{y h}}{f_{c 0}}}-2 \times \frac{0.5 K_{e} \rho_{h} f_{y h}}{f_{c 0}}-1.254\right)$,

$\varepsilon_{c u}=0.004+\frac{1.4 \rho_{h} f_{y h} \varepsilon_{u}}{f_{c 0}}$

where $K_{e}$ is the effective confined coefficient of section; $\rho_{h}$ is the residual volumetric ratio of corroded transverse reinforcement; $f_{y h}$ and $\varepsilon_{u}$ are the yield strength and ultimate strain of corroded transverse reinforcement, respectively.

\section{Time-Dependent Fragility Method}

In this study, the analytical seismic fragility is applied to quantify the seismic damage probability of bridges. Fragility functions describe the conditional damage probability of a component or structure exceeding a specific damage state (DS) for a given ground motion intensity measure (IM) [22]. Considering the time-dependent effect, the damage probability of aging bridges at $t$ year after construction can be described as follows:

$$
P[D S(t)>d s(t) \mid \mathrm{IM}=i m]=P\left[\frac{S_{D}(t)}{S_{C \mid d s}(t)} \mid \mathrm{IM}=i m\right],
$$

where $S_{D}(t)$ is a time-dependent structural seismic demand for the specific IM; $S_{C \mid d s}(t)$ is the time-dependent structural seismic capacity corresponding to the given DS.

For a specific service time, $S_{D}(t)$ and $S_{C \mid d s}(t)$ can be assumed to follow lognormal distributions. Therefore, the time-dependent seismic fragility functions take the following form:

$$
P[D S(t)>d s(t) \mid \mathrm{IM}=i m]=P\left[\frac{\mu(t)}{\sigma(t)} \mid \mathrm{IM}=i m\right],
$$

where $\mu(t)$ and $\sigma(t)$ are the median estimate and standard deviation of $\ln \left[S_{D}(t) / S_{C \mid d s}(t)\right]$, respectively; $\Phi(\cdot)$ is the standard normal cumulative distribution function.

Generally, $\mu(t)$ can be predicted by a power model using the least-square method as follows:

$$
\mu=a(t) \cdot \ln (\mathrm{IM})+b(t),
$$

where $a(t)$ and $b(t)$ are the time-dependent regression coefficients.

Moreover, the standard deviation $\sigma(t)$ is determined as follows:

$$
\sigma(t)=\sqrt{\frac{\sum_{i=1}^{N}\left[y_{i}(t)-\mu_{i}(t)\right]^{2}}{N-2}},
$$

where $y_{i}(t)$ and $\mu_{i}(t)$ are the actual and predicted values of $\ln \left[S_{D}(t) / S_{C \mid d s}(t)\right]$, respectively; $N-2$ represents the freedom degree of simulations when the log-linear model is adopted in the probabilistic seismic demand analysis.

Combining the above corrosion analysis method and the time-dependent seismic fragility method, we can perform the probability seismic damage assessment of aging RC bridges subject to spatial chloride-induced corrosion. Overall, Figure 2 summarizes the analysis procedure, and the critical steps are included as follows:

(1) Corrosion Analysis. For given details of piers (e.g., the thickness of concrete cover, the diameter of piers, the arrangement of reinforcing steels, the water binder ratio of concrete, the properties of materials, etc.), the corrosion initial time of reinforcing steels under different exposure conditions can be calculated (equations (2) and (3)). Subsequently, the time-dependent percentage mass loss of reinforcing steels is determined by using the pitting corrosion model (equations (4) (10)) and time-dependent uniform corrosion rate model (equations (11) and (12)). On this basis, the time-dependent properties of reinforcing steels, concrete cover, and confined concrete in the corroded piers are determined (equations (13) (18)).

(2) Bridge Model Updated. The exposure conditions of each part of piers should be first determined according to the layout of bridge and the hydrological data (e.g., high level, low level, height of marine splash, etc.). Subsequently, the finite element model of bridge at pristine condition is developed. Moreover, elements of piers should be divided reasonably to ensure that each element of piers is located in the same exposure condition. For a specified time, the degeneration properties of various materials are obtained from step (1) and are associated with each part of piers.

(3) Time-Dependent Seismic Fragility Analysis. The nonlinear time history and nonlinear static analysis are performed to obtain seismic demand and seismic capacity of components, respectively. By comparing the seismic demand and seismic capacity of components, the seismic demand capacity ratio can be determined, and the median estimate and standard deviation in seismic fragility function are calculated by using the regression fitting (equations (21) and (22)). By repeating step (2) and step (3), the timedependent seismic fragility functions can be developed (equation (20))

\section{Case Study}

4.1. Bridge Description. To investigate the seismic damage of aging bridges, a four-span continuous RC bridge is taken as the case study, as shown in Figure 3(a). Each span of the bridge is $30 \mathrm{~m}$. The deck consists of four box-shaped concrete girders. The width and height of deck are $13.25 \mathrm{~m}$ and $1.6 \mathrm{~m}$, respectively. Each pier bent consists of two circular 


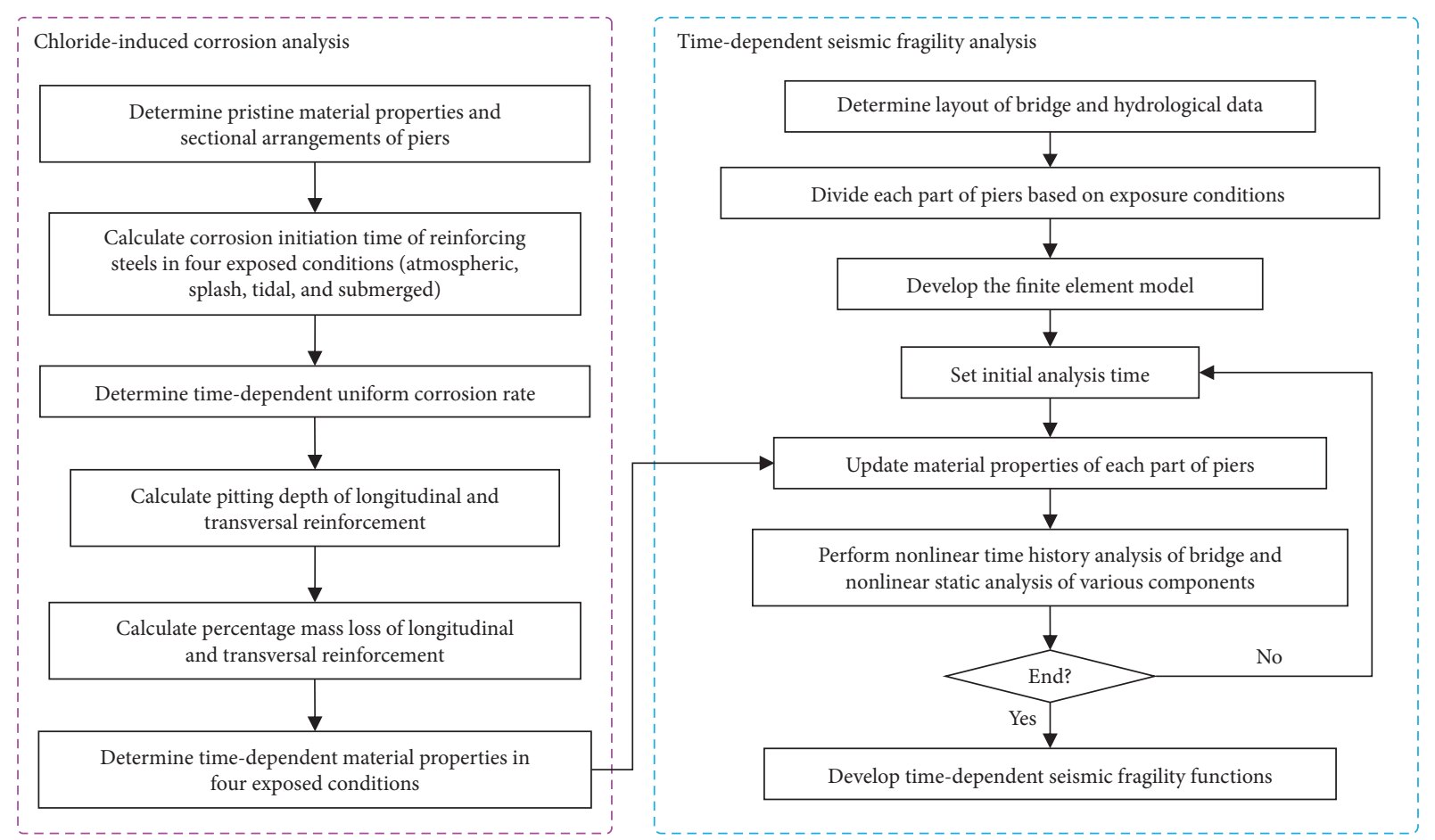

FIGURE 2: Flowchart of probabilistic seismic damage assessment for aging RC bridges subject to spatial chloride-induced corrosion.

columns with $1.5 \mathrm{~m}$ diameter. The heights of three piers are $6 \mathrm{~m}, 10 \mathrm{~m}$, and $8 \mathrm{~m}$, respectively. The concrete strengths of the substructure and superstructure are $30 \mathrm{MPa}$ and $50 \mathrm{MPa}$, respectively. Each column consists of 48 longitudinal reinforcements with a diameter of $28 \mathrm{~mm}$ and yield stress of $335 \mathrm{MPa}$. The longitudinal reinforcement ratio is $1.67 \%$. Moreover, rebars with a diameter of $12 \mathrm{~mm}$ and yield stress of $335 \mathrm{MPa}$ are used as circular stirrups with a spacing of $80 \mathrm{~mm}$ (corresponding to a volumetric ratio of $0.6 \%$ ). The thickness of concrete cover is $50 \mathrm{~mm}$. Four rubber bearings are installed at the top of each bent, and four PTFE elastomeric bearings are located on the top of each abutment. In this study, two analysis cases are considered: (a) the bridge located in shallow water and (b) the bridge located in deep water. The high water level and low water level of two analysis cases are present in Figures 3(b) and 3(c). The height of marine splash is assumed to be $1 \mathrm{~m}$.

4.2. Finite Element Modelling. The finite element model is developed by OpenSees (Open System for Earthquake Engineering Simulation), the PEER Center's finite element platform [23]. Figure 3(a) shows the three-dimensional finite element model of bridge. Overall, the girder is modelled by the linear elastic beam-column elements and the nonlinear beam-column element with fiber cross sections is used to simulate the piers. The element of piers is divided based on the different exposure conditions. The piers fibers use Concrete04 and Steel02 for concrete and longitudinal reinforcement, respectively. The zero-length element with the elastic and elastic PP materials is used to simulate the rubber bearings and the PTFE bearings, respectively. Shear keys are simulated in parallel with the hysteretic and elastic PP gap materials. Furthermore, the interaction effects of abutments and backfill soil are considered by using hyperbolic gap material. The expansion joints at the deck end are modelled through the gap elements. In order to consider the effects of spatial chloride-induced corrosion, five group time-dependent finite element models of bridge under different time after construction (i.e., pristine, 20, 40, 60, 80, and 100 years, etc.) are developed according to the above modelling approach. The Monte Carlo approach is used to fully consider the uncertainties in the development of seismic fragility curves. Based on the finite element model, modal analysis of the bridge at pristine condition is performed to determine the fundamental periods. The result shows that the fundamental periods of model in longitudinal and transverse directions are $1.67 \mathrm{~s}$ and $1.35 \mathrm{~s}$, respectively.

4.3. Ground Motions. To fully consider the uncertainties of ground motions, a broad range of intensities should be included in a reasonable ground motion suite. In this respect, 100 ground motions are selected to perform nonlinear time history analysis [24]. The selected ground motions include different source-to-site distances and magnitudes (Figure 4(a)): small magnitude and small epicentre distances (SMSR), small magnitude and large epicentre distances (SMLR), large magnitude and small epicentre distances (LMSR), large magnitude and large epicentre distances (LMLR), and near field (NF). Moreover, the spectra acceleration at the geometric mean of the periods with $5 \%$ damping $\mathrm{SA}_{\mathrm{GM}}$ is chosen as intensity measure in this study [25]. The linear acceleration spectra and the distribution of $\mathrm{SA}_{\mathrm{GM}}$ of 100 ground motions are present in Figure 4(b). 


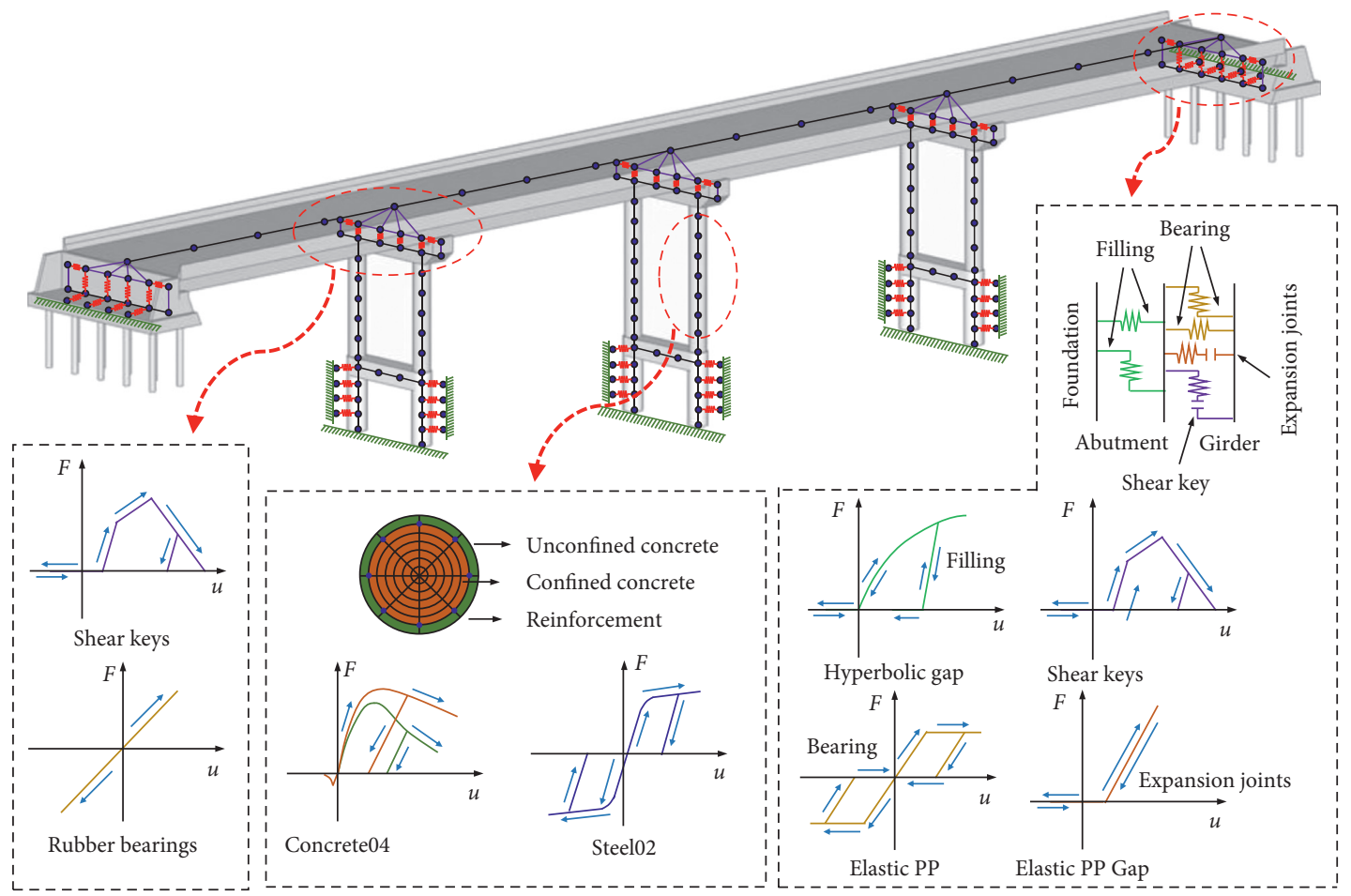

(a)

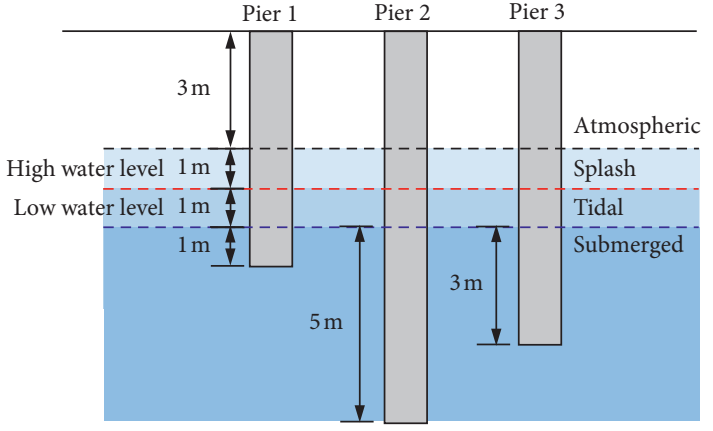

(b)

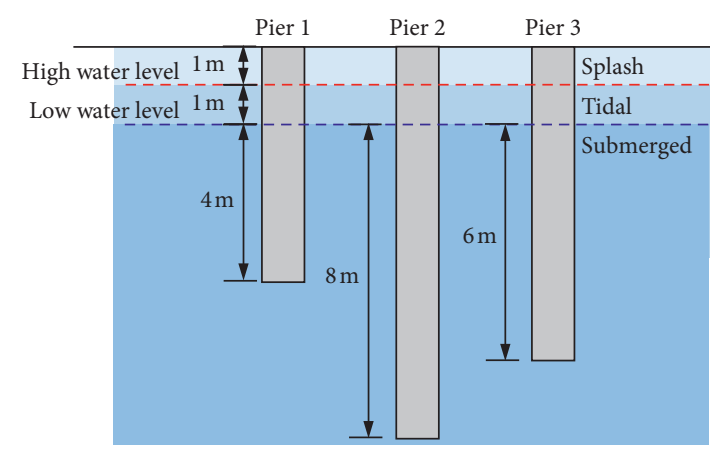

(c)

FIgURE 3: Schematic and finite element model of case study bridge.

\section{Corrosion Process and Seismic Capacity Analysis}

5.1. Corrosion Process of Reinforcing Steels. To consider the uncertainties during the corrosion process, 10000 samples are randomly generated using the Monte Carlo simulation method. Figure 5 illustrates the probability density of corrosion initiation time of transverse and longitudinal reinforcement. Overall, the significant dispersions of corrosion initiation time can be observed owing to the uncertainty of chloride ions diffusion process and outside environment. The corrosion initiation time of reinforcing steels can be well described by the lognormal distributions. Given that the distance varies in the outside environment, the transverse reinforcement presents a relatively smaller corrosion initiation time than the longitudinal reinforcement. Moreover, the corrosion of reinforcing steels exposure in tidal zone is most likely to be corroded, followed by the splash zone, atmospheric zone, and submerged zone. Furthermore, it should be noted that the general thickness of concrete cover (i.e., $50 \mathrm{~mm}$ ) is unlikely to effectively prevent the corrosion of reinforcing steels of bridges in a marine environment during the lifetime.

Based on the corrosion initiation time, the time-dependent corrosion level of reinforcing steels can be determined. Figure 6 presents the distribution and mean value of the percentage mass loss of corroded transverse and longitudinal reinforcement at different time. As expected, the corrosion level of reinforcing steels also exhibits significant dispersions. From the mean of the percentage mass loss, we can observe that the corrosion level of transverse reinforcement is obviously larger than that of the longitudinal reinforcement due to its smaller diameter and shorter corrosion initiation time. Similar to the corrosion initiation time, the corrosion of reinforcing steels in tidal zone is more serious than that in other exposure conditions. 


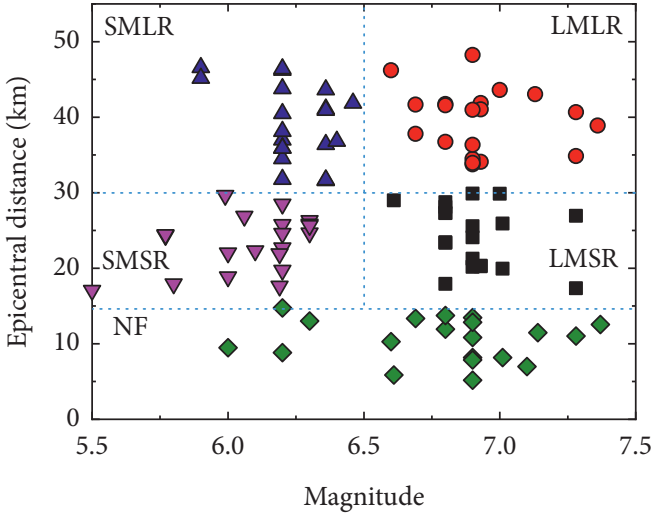

(a)

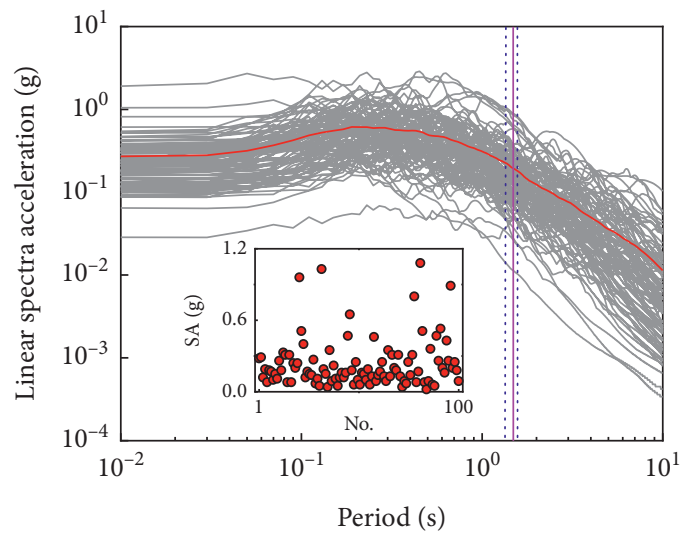

(b)

Figure 4: (a) R-M distribution and (b) acceleration response spectra of 100 ground motions $(\xi=0.05)$.

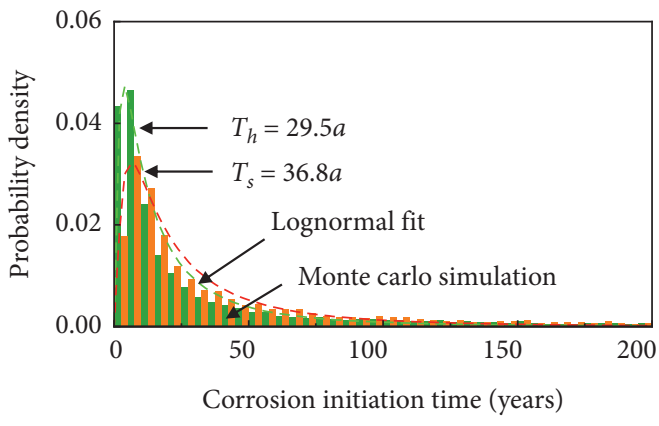

(a)

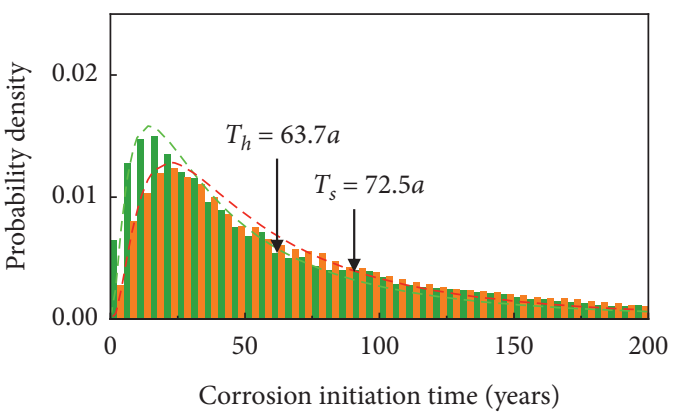

(c)

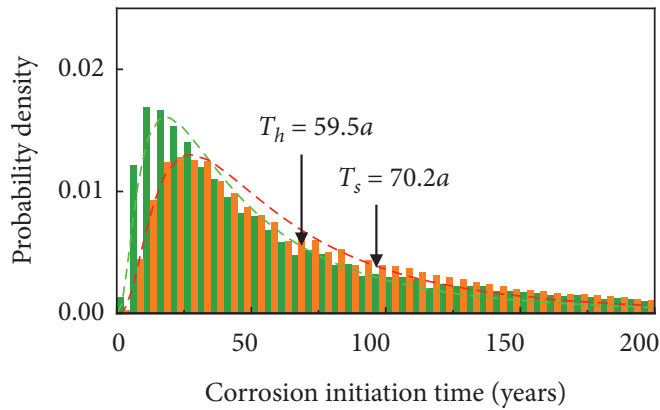

(b)

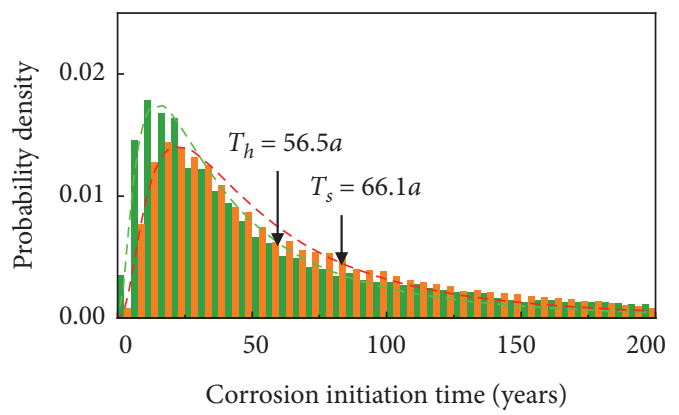

(d)

Figure 5: Probability distribution of corrosion initiation time in (a) tidal zone, (b) atmospheric zone, (c) submerged zone, and (d) splash zone.

On the other hand, a nonlinear relationship between time and the mean of percentage mass loss of reinforcing steels can be observed. In particular, the increase rate of the percentage mass loss is relatively small at initial years. One reason is that most of samples will not be corroded at the initial years, and another reason is that the influence of corrosion depth on the pitting corrosion area is relatively slight when the corrosion level is low. Meanwhile, the percentage mass loss has a remarkable increase as time increases, and the increase rate keeps an approximate constant value. Moreover, the increase rate of the percentage mass loss of transverse reinforcements decreases when the corrosion level exceeds a threshold value (about
$50 \%$ percentage mass loss). It is because the sensitivities of pitting corrosion area to the corrosion depth decrease when the corrosion level is high.

5.2. Seismic Capacity of Piers. To investigate the influence of chloride-induced corrosion on the seismic capacity of piers, the properties of degradation materials should be determined. Table 2 shows the time-dependent properties of reinforcing steels and concrete. Based on the material properties and nonlinear static analysis, the time-dependent moment-curvature relationships of cross section of piers are obtained, as shown in Figure 7. 


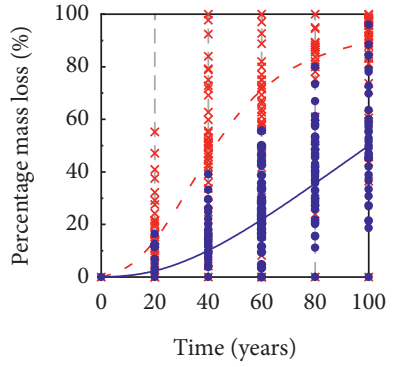

(a)

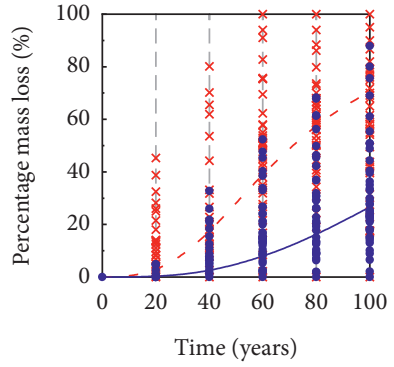

(b)

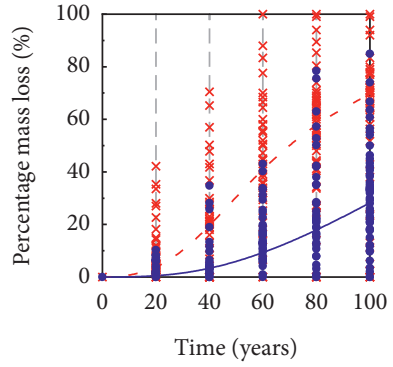

(c)

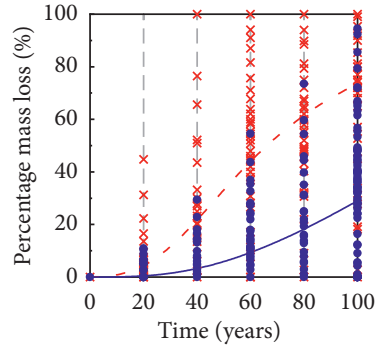

(d)

FiguRE 6: Distribution and mean value of the percentage mass loss of reinforcement at different years in (a) tidal zone, (b) atmospheric zone, (c) submerged zone, and (d) splash zone.

TABLE 2: Time-dependent material properties under four categories of exposure conditions.

\begin{tabular}{|c|c|c|c|c|c|c|}
\hline Material parameters & 0 & 20 & 40 & 60 & 80 & 100 \\
\hline \multicolumn{7}{|l|}{ Tidal zone } \\
\hline Yield strength of longitudinal reinforcement & 335 & 332 & 319 & 288 & 267 & 252 \\
\hline Compressive strength of unconfined concrete & 30.0 & 20.4 & 12.8 & 8.7 & 6.3 & 4.7 \\
\hline Compressive strength of confined concrete & 37.5 & 34.0 & 32.8 & 31.9 & 31.5 & 31.3 \\
\hline Ultimate strain of confined concrete & 0.0116 & 0.0077 & 0.0061 & 0.0052 & 0.0048 & 0.0047 \\
\hline \multicolumn{7}{|l|}{ Submerged zone } \\
\hline Yield strength of longitudinal reinforcement & 335 & 335 & 331 & 322 & 308 & 291 \\
\hline Compressive strength of unconfined concrete & 30.0 & 28.7 & 23.6 & 18.7 & 14.7 & 11.7 \\
\hline Compressive strength of confined concrete & 37.5 & 34.7 & 34.0 & 33.3 & 32.6 & 32.1 \\
\hline Ultimate strain of confined concrete & 0.0116 & 0.0087 & 0.0076 & 0.0066 & 0.0059 & 0.0054 \\
\hline \multicolumn{7}{|l|}{ Atmospheric zone } \\
\hline Yield strength of longitudinal reinforcement & 335 & 334 & 330 & 320 & 306 & 289 \\
\hline Compressive strength of unconfined concrete & 30.0 & 28.1 & 22.9 & 18.6 & 15.1 & 12.3 \\
\hline Compressive strength of confined concrete & 37.5 & 34.6 & 34.0 & 33.3 & 32.7 & 32.2 \\
\hline Ultimate strain of confined concrete & 0.0116 & 0.0087 & 0.0076 & 0.0067 & 0.0060 & 0.0055 \\
\hline \multicolumn{7}{|l|}{ Splash zone } \\
\hline Yield strength of longitudinal reinforcement & 335 & 334 & 330 & 320 & 305 & 287 \\
\hline Compressive strength of unconfined concrete & 30.0 & 28.1 & 22.7 & 17.7 & 13.9 & 11.1 \\
\hline Compressive strength of confined concrete & 37.5 & 34.6 & 33.9 & 33.0 & 32.4 & 32.0 \\
\hline Ultimate strain of confined concrete & 0.0116 & 0.0086 & 0.0074 & 0.0064 & 0.0057 & 0.0053 \\
\hline
\end{tabular}

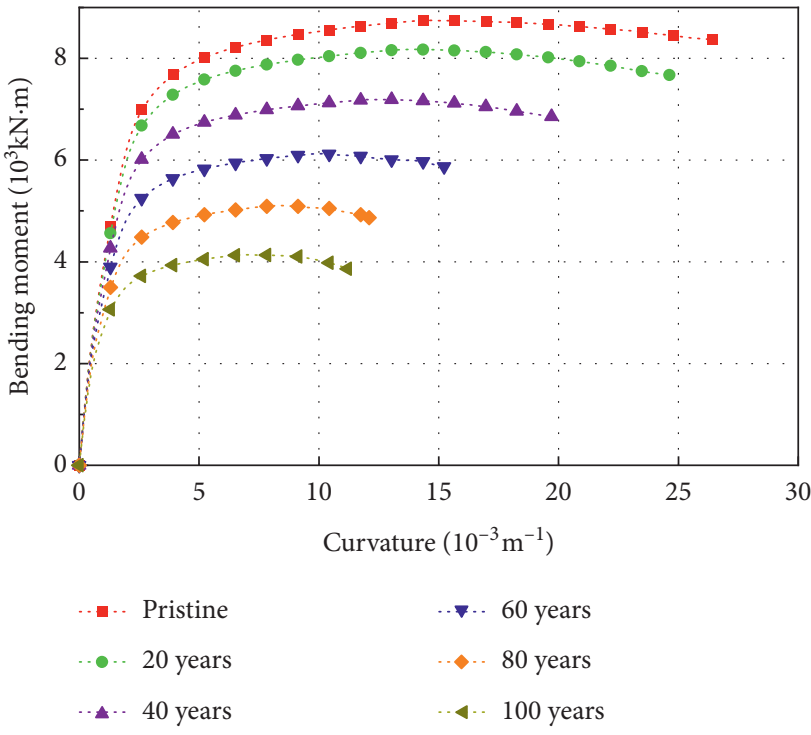

FIGURE 7: Time-dependent moment-curvature relationships of piers in tidal zone.
Referring to Figure 7, it is seen that the effects of corrosion on the initial stiffness of cross section are relatively slight. Meanwhile, the moment capacities and the ultimate curvatures of cross section exhibit a remarkable degradation. The phenomenon is consistent with the findings from some experiments $[26,27]$. However, an increase in the ultimate curvature of cross section after corrosion can be observed in some previous studies $[28,29]$. The main reason is that these studies ignore the degradation effect of confined concrete on the seismic capacity of corroded piers. In fact, the corrosion of longitudinal reinforcement will decrease the compression area of cross section of piers. Had the reduction of ultimate compression strain of confined concrete not been considered, the ultimate curvature of corroded piers would have increased slightly rather than decreasing significantly.

To further investigate seismic capacity of corroded piers, the curvatures of cross section in various exposure conditions at four-level damage states (i.e., slight, moderate, extensive, and complete [30]) are shown in Figure 8. Overall, two different variation trends of the curvature 

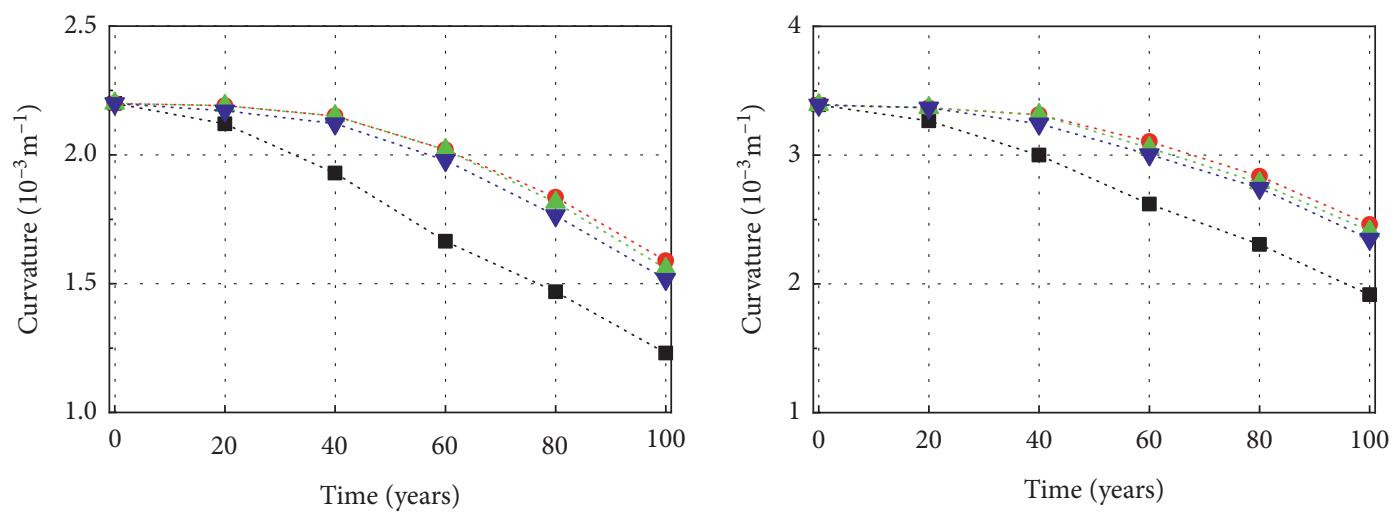

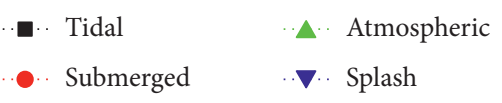

(a)

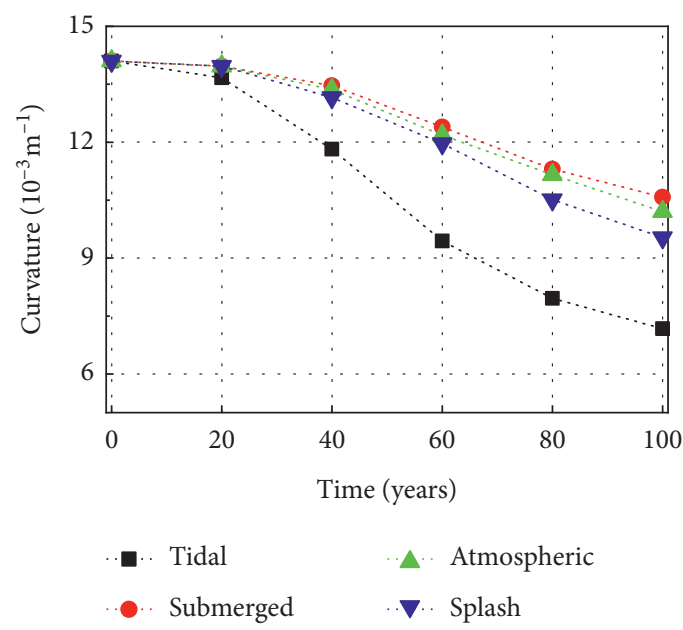

(c)

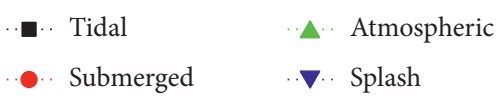

(b)

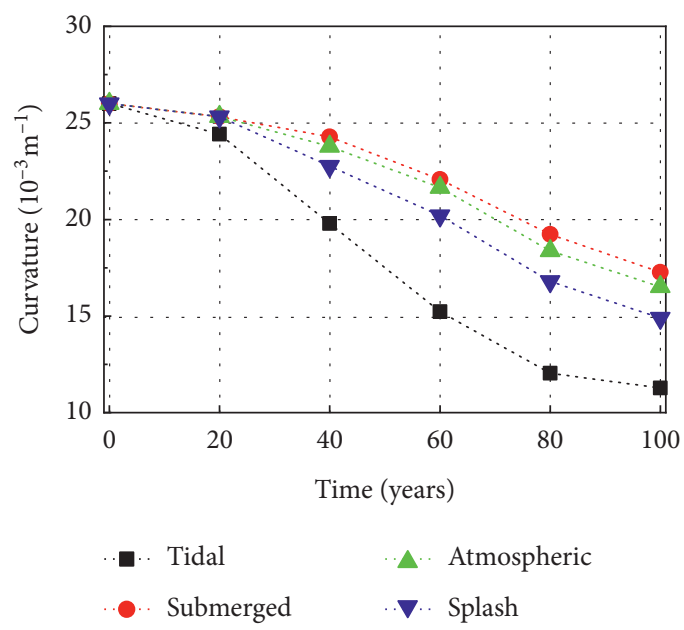

(d)

Figure 8: Curvature capacity of piers at (a) slight, (b) moderate, (c) extensive, and (d) complete damage states.

capacities at four damage states can be observed. As the slight and moderate damage states are defined as the first longitudinal reinforcement yields and the fully formed plastic hinge of section, respectively, the corresponding curvatures highly depend on the properties of longitudinal reinforcement. In consequence, the curvature capacities of piers at these two damage states exhibit a similar variation trend to the percentage mass loss of corroded longitudinal reinforcement. Meanwhile, the compressive strength and ultimate strain of confined concrete play an important role in the curvature capacity of piers at extensive and complete damage states. Therefore, the variation trend of curvature capacity of piers at these two damage states is similar to that of the percentage mass loss of corroded transverse reinforcement. Moreover, the curvature capacity of piers in tidal zone is significantly lower than that of other exposure conditions, as expected. In particular, the maximum reduction ratios of curvatures capacity in various exposure conditions at extensive damage states are $49 \%, 25 \%, 28 \%$, and $32 \%$, respectively.

\section{Seismic Damage Assessment of Aging Bridge}

6.1. Fragility Analysis of Piers. According to the damage assessment procedure, the time-dependent seismic fragility functions of bridges can be obtained. Figure 9 presents the time-dependent fragility surfaces of three piers in longitudinal direction when the bridge is located in shallow water. Due to the stiffness discrepancy of piers, the fragility surfaces of various piers exhibit significant different. With the increase of service time, the fragility surfaces of each pier at four damage states present upward trends. This is particularly seen in the fragility surfaces at extensive and complete damage states. For example, for an SA value of $0.3 \mathrm{~g}$, the probabilities of pier 1 exceeding four damage states increase by $12 \%, 20 \%, 73 \%$, and $195 \%$, respectively. It is indicated that the corrosion has negative effects on the seismic damage of piers. Moreover, the different variation degrees result in the decrease of gap between fragility surfaces at each damage state. It is revealed that the ductility level of piers will significantly decrease, entailing the damage state of corroded 


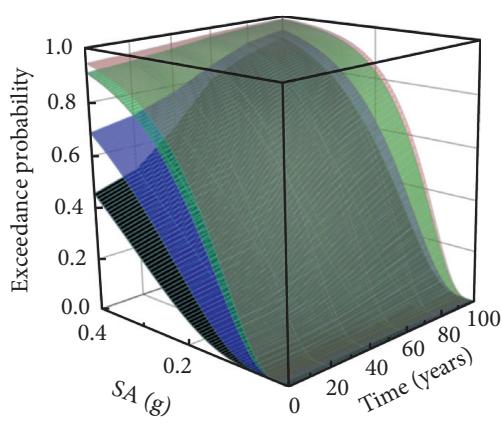

(a)

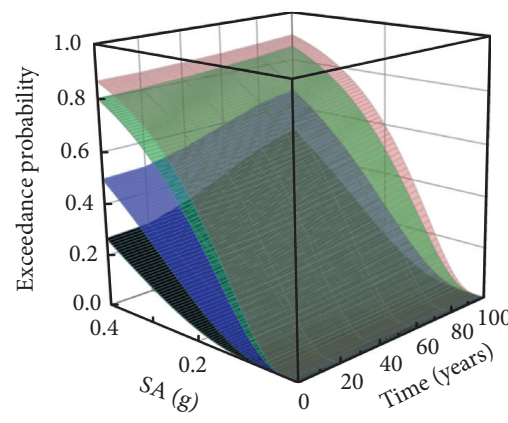

(b)

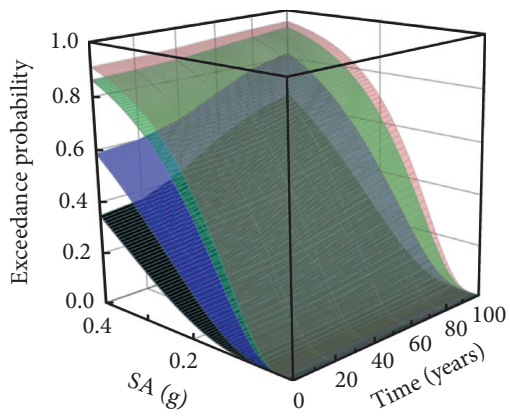

(c)

Figure 9: Time-dependent fragility surfaces of (a) pier 1, (b) pier 2, and (c) pier 3 in longitudinal direction.

piers much easier to transform from a low level to a high level during earthquakes.

On the other hand, it can be observed from Figure 9 that the damage probabilities of piers at various damage states demonstrate nonlinear variation trends with the increase of time. Specifically, the damage probabilities of piers at 20 years are close to those at pristine condition because the degradation of piers mainly occurs at 30 40 years after construction. Moreover, the damage probabilities of piers at slight and moderate damage states steadily increase after 40 years. Meanwhile, the increase rates of damage probabilities at extensive and complete damage states reduce after 80 years. Overall, the phenomenon is similar to the variation trends of curvature capacities (see Figure 8). It can be inferred that the seismic capacities of piers strongly affect the seismic fragility of piers.

In order to investigate the effects of spatial chlorideinduced corrosion on the damage distribution of piers, Figure 10 shows the seismic fragility contour maps of pier 1 at pristine condition and 100 years after construction. Depending on the inertia force distributions of piers during earthquakes, the damage probability distribution of piers in longitudinal direction at pristine condition follows an approximate linear triangle pattern, whereas the damage in transverse direction forces on the two ends of piers and decreases from two ends to the middle of piers. However, a jaggedness damage probability distribution of piers can be observed in some cases after spatial chloride-induced corrosion. In particular, the section at the low and/or high water levels may become more vulnerable than the adjacent sections in two directions. The reason is that seismic capacities of the sections exposed in the tidal zone between the low water level and high water level will exhibit more significant degradation. Therefore, the spatial chloride-induced corrosion not only increases the seismic damage probability of piers but also may alter the damage probability distribution of piers.

To clearly illustrate the damage distribution of various piers, Figure 11 presents the distribution of the median SA (corresponding to a $50 \%$ damage probability) exceeding moderate damage state of each pier at pristine condition and 100 years after construction. A visible alteration of damage distribution in two directions can be observed from the pier located in shallow water. Meanwhile, the damage distribution of pier in transverse direction will be altered when it is located in shallow water. Moreover, the movement of inflection points in piers can be found after alteration of damage distribution. It should be noted that the probability exceeding moderate damage state of section at the low water level may exceed that of sections at two ends of piers after corrosion. It can be inferred that the formation of plastic hinges of section at the low water level will be earlier than that of two-end sections. In other words, the spatial chlorideinduced corrosion may alter the yield sequence of piers during earthquakes. On the other hand, the alteration of damage distribution is the most significant in pier 1 followed by pier 3 and pier 2 when the bridge is located in shallow water. Meanwhile, an opposite trend can be found from the bridge located in deep water. It is indicated that the height of piers and water level will commonly affect the damage distribution of piers. A further discussion in this regard is presented in Section 7.

6.2. Fragility Analysis of Other Components. Previous investigation mainly focused on the effects of corrosion on the seismic damage of piers. In fact, the degradation of piers will affect the dynamic characteristics and seismic response of the whole bridge. To fully investigate the seismic damage of aging bridge, the seismic fragility functions of shear keys, rubber bearings, and PTFE sliding bearings are developed. Table 3 shows the seismic capacities of these components at different damage states.

Figure 12 shows the time-dependent fragility curves of components at moderate and complete damage states when the bridge is located in shallow water. Due to the stiffness discrepancy between various piers and abutments, the damage of components at abutment is always more serious than that of components at piers. Moreover, the components at pier 1 are the most vulnerable followed by the components at pier 3 and pier 2. On the other hand, a decrease in damage probability of various components with increasing time can be observed from the figure, which is opposite to that of piers. When $S A=0.2 \mathrm{~g}$, the probabilities of shear keys at abutment, PTFE sliding bearings at abutment, and rubber bearings at pier 1 exceeding moderate damage reduce by $24.1 \%, 35.1 \%$, and $29.0 \%$, respectively. The main reason is that the corrosion of piers will decrease the inertia force in 


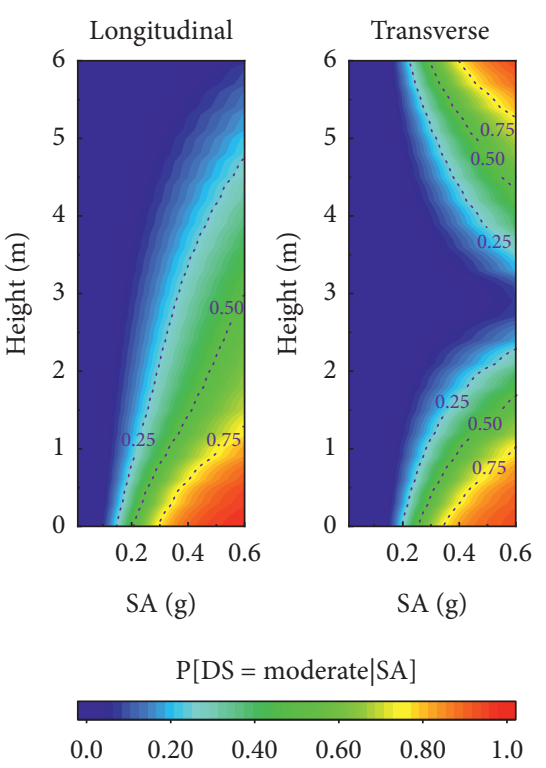

(a)

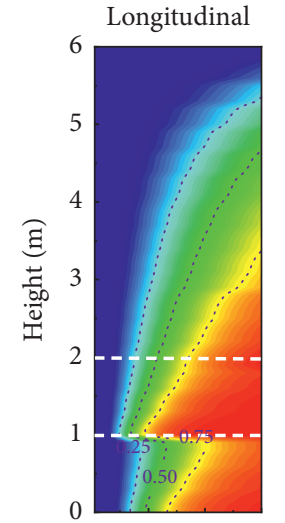

$0.2 \quad 0.4 \quad 0.6$

SA (g)

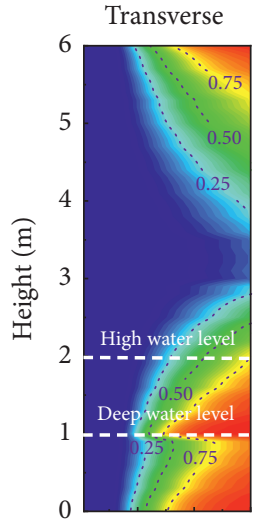

$0.2 \quad 0.4 \quad 0.6$

$\mathrm{SA}(\mathrm{g})$

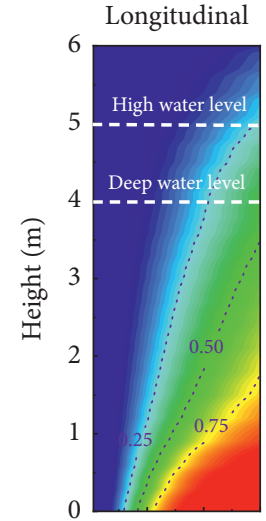

$0.2 \quad 0.4 \quad 0.6$ SA (g)

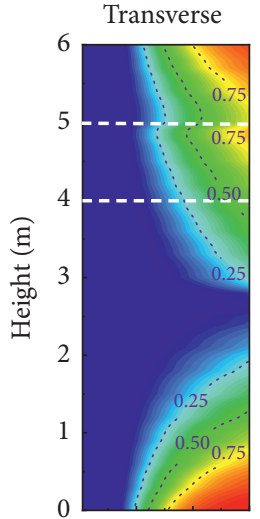

$0.2 \quad 0.4 \quad 0.6$

SA (g)

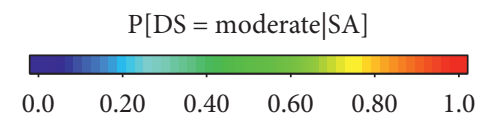

(b)

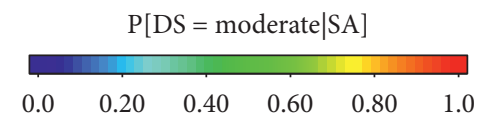

(c)

FIGURE 10: Fragility contour maps of pier 1 (a) at pristine condition, (b) at 100 years after construction in shallow water, and (c) at 100 years after construction in deep water.

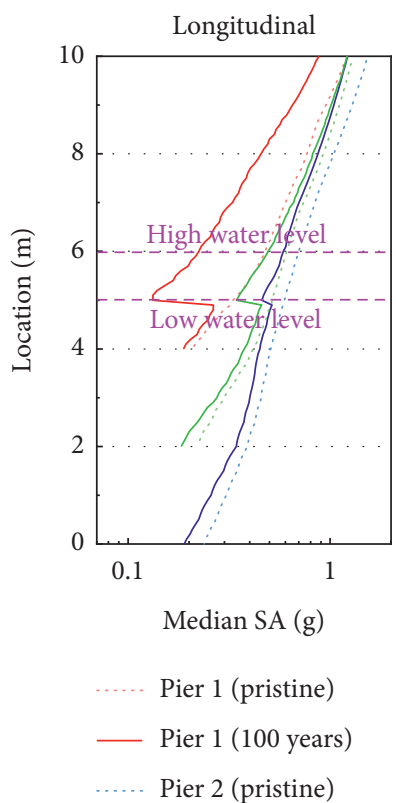

(a)

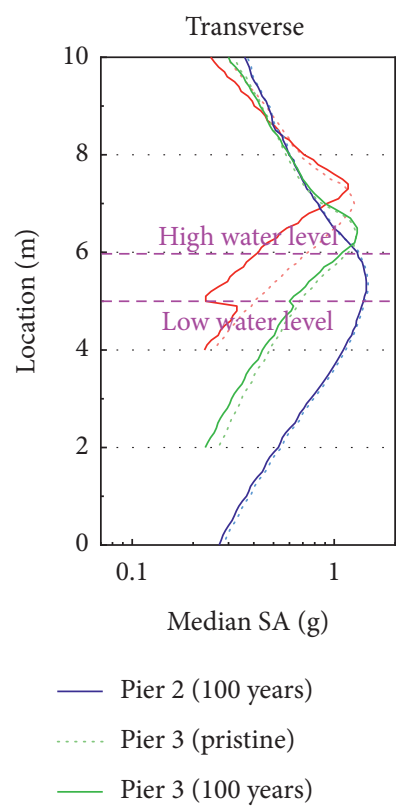

)
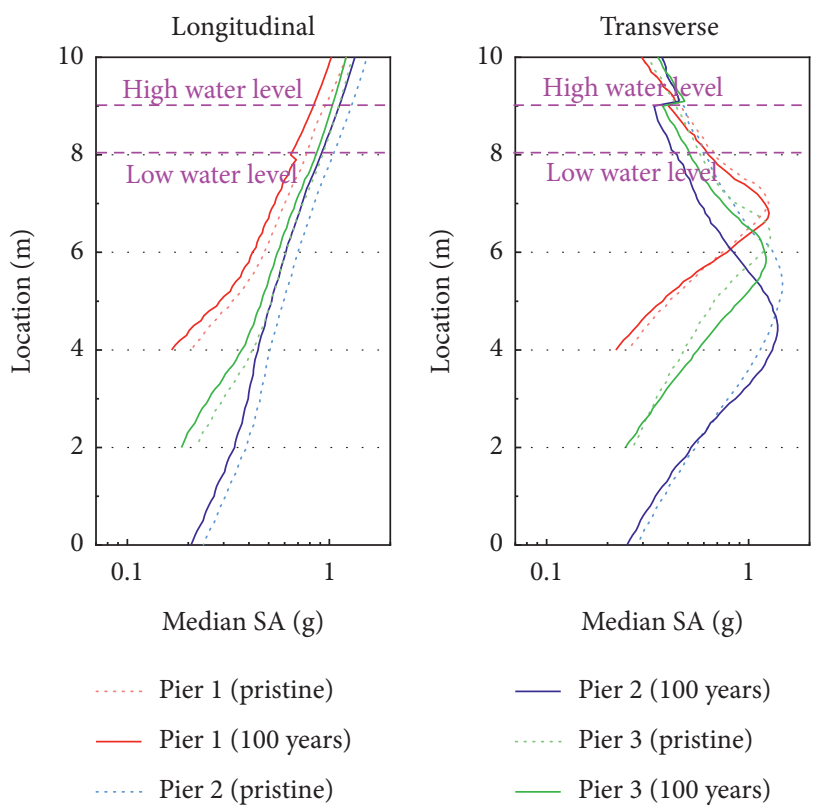

(b)

FIgURE 11: Distribution of median SA of piers at moderate damage state: (a) in shallow water and (b) in deep water.

TABLE 3: Definition of damage states of different components.

\begin{tabular}{llcccc}
\hline Component & EDP & Slight & Moderate & Extensive & Complete \\
\hline Shear keys & Deformation $(\mathrm{mm})$ & 5.2 & 51 & 70 & 130 \\
PTFE sliding bearings & Deformation $(\mathrm{mm})$ & 80 & 150 & 200 & 300 \\
Rubber bearings & Deformation $(\mathrm{mm})$ & 80 & 120 & 160 & 200 \\
\hline
\end{tabular}

the bridge, resulting in a decrease of seismic response of other components. In this case, the corrosion of piers may have a beneficial effect on the seismic damage of these components. Because only the variation of seismic demand is considered in the development of seismic fragility of these components, the variation degree of fragility curves is 

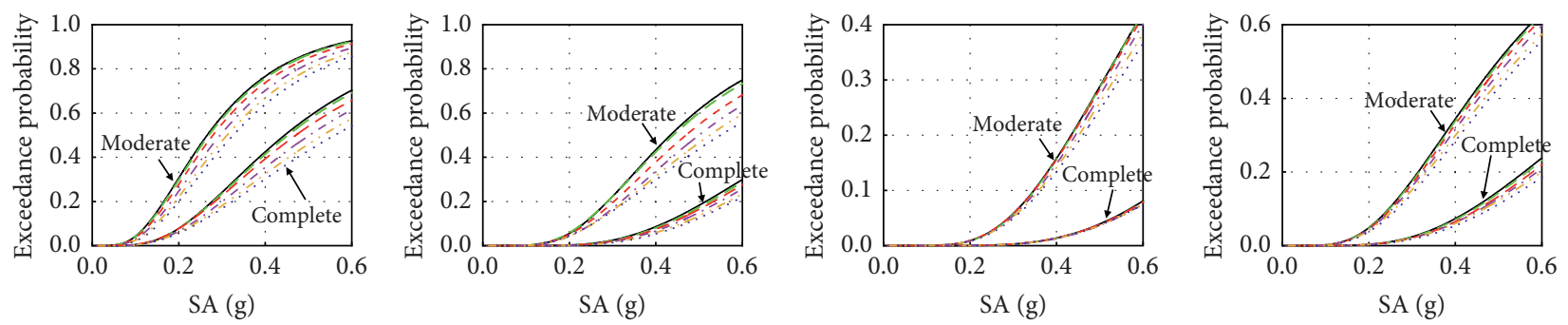

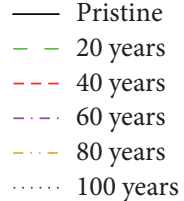

(a)
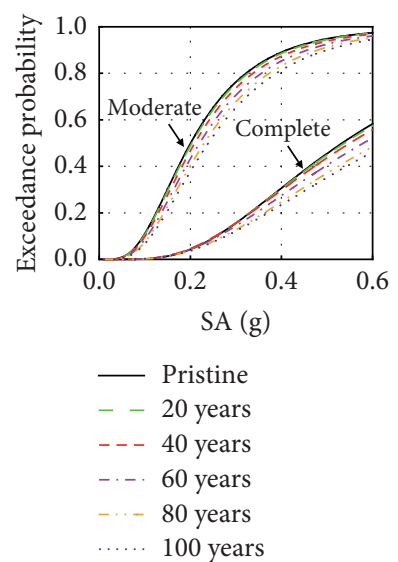

(e)

$$
\begin{aligned}
& \text { —- Pristine } \\
& --20 \text { years } \\
& \ldots--40 \text { years } \\
& \ldots-.60 \text { years } \\
& \ldots-80 \text { years } \\
& \ldots . .60 \text { years }
\end{aligned}
$$

(b)

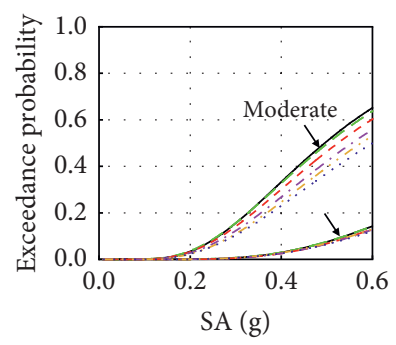

- Pristine

- -20 years

- - 40 years

-. 60 years

80 years

..... 100 years

(f)

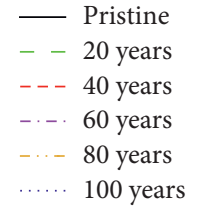

(c)

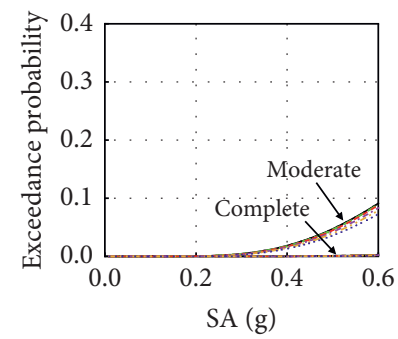

- Pristine

- -20 years

- - 40 years

-.-. 60 years

80 years

…. 100 years

(g)

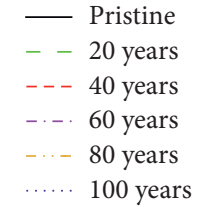

(d)

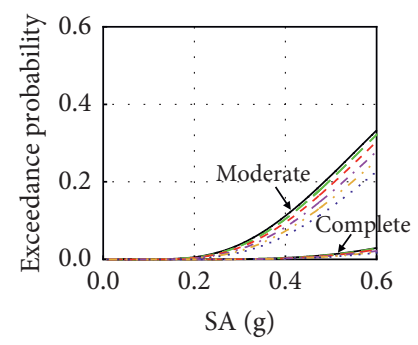

_ Pristine

- 20 years

- - 40 years

-. 60 years

80 years

... 100 years

(h)

Figure 12: Time-dependent fragility curves of (a) shear keys at abutment, (b) shear keys at pier 1, (c) shear keys at pier 2, (d) shear keys at pier 3, (e) PTFE sliding bearings at abutment, (f) rubber bearings at pier 1, (g) rubber bearings at pier 2, and (h) rubber bearings at pier 3.

relatively slighter than that of piers. Additionally, Table 4 lists the median SAs of some critical components. By comparing the seismic fragility of piers in Figure 11(a), we can observe that the PTFE sliding bearing at abutment is the most vulnerable component at slight damage state at pristine condition. Meanwhile, pier 1 tends to dominate the vulnerability of the bridge at 100 years after construction. It is indicated that the opposite degradation trends between piers and other components may change the most vulnerable component in the whole bridge.

Figure 13 presents the fragility curves of various components at extensive damage state. The difference between fragility curves in deep water and shallow water indicates that the water level will affect the damage probability of other components. For the components at abutment and pier 1, the damage probability in shallow water is relatively smaller than that in deep water. On the contrary, the damage probability of components at pier 3 in shallow water is relatively larger than that in deep water. Combined with the previous analysis, it seems that the alteration of damage distribution of piers seems to aggravate the variation degree of damage probability of other components.

\section{Evolution Probability of Yield Sequence of Corroded Piers}

Modern RC piers are generally designed to dissipate energy during strong earthquakes by permitting the controlled formation of plastic hinges. In this aspect, detailed design of the plastic hinges is necessary to ensure that piers have enough dissipation of energy. Meanwhile, the displacement ductility capacity of piers should be determined according to the distribution of plastic hinges. Therefore, the plastic hinges of piers should be predetermined during the ductile seismic design. In general, the plastic hinges are expected to form at the bottom and/or top of piers. However, as mentioned, the spatial chloride-induced corrosion may alter the yield sequence of corroded piers. In this case, it is important to determine the yield sequence of the corroded piers during the ductile seismic design.

In this section, we propose a method to determine the evolution probability of yield sequence of piers. Based on the results in Section 6, the plastic hinges of corroded piers may appear at four sections: (1) the bottom section of piers, (2) the top section of piers, (3) the section at low water level, and 
TABLE 4: Median SAs of various components.

\begin{tabular}{lccccccc}
\hline Components & Damage states & Pristine & 20 years & 40 years & 60 years & 80 years & 100 years \\
\hline \multirow{3}{*}{ Shear keys at abutment } & Slight & 0.171 & 0.173 & 0.179 & 0.188 & 0.197 & 0.205 \\
& Moderate & 0.266 & 0.27 & 0.28 & 0.296 & 0.312 & 0.326 \\
& Extensive & 0.307 & 0.312 & 0.324 & 0.344 & 0.363 \\
& Complete & 0.445 & 0.452 & 0.471 & 0.503 & 0.533 & 0.38 \\
& Slight & 0.122 & 0.123 & 0.126 & 0.131 & 0.136 \\
PTFE bearings at abutment & Moderate & 0.201 & 0.203 & 0.209 & 0.22 & 0.23 & 0.141 \\
& Extensive & 0.339 & 0.344 & 0.356 & 0.376 & 0.395 & 0.412 \\
& Complete & 0.533 & 0.542 & 0.563 & 0.598 & 0.632 & 0.663 \\
\hline \multirow{4}{*}{ Rubber bearings at pier 1 } & Slight & 0.28 & 0.287 & 0.293 & 0.31 & 0.33 \\
& Moderate & 0.495 & 0.51 & 0.53 & 0.56 & 0.58 & 0.35 \\
& Extensive & 0.743 & 0.77 & 0.8 & 0.83 & 0.86 & 0.6 \\
& Complete & 0.99 & 1.04 & 1.08 & 1.113 & 1.16 \\
\hline
\end{tabular}

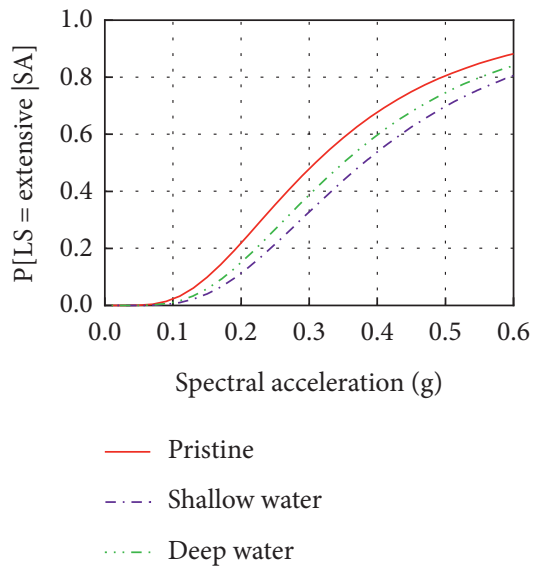

(a)

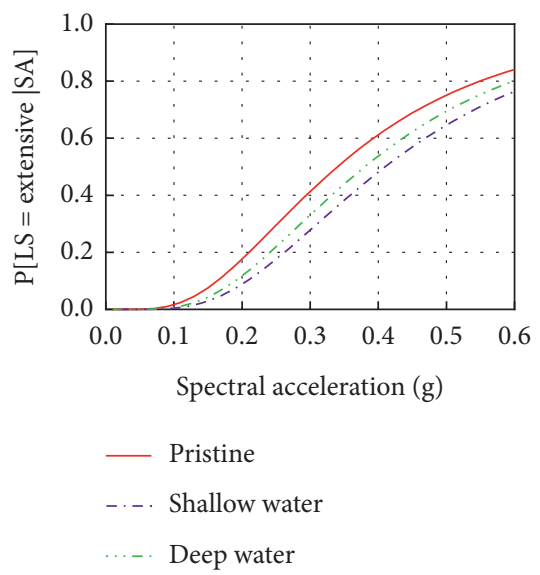

(d)

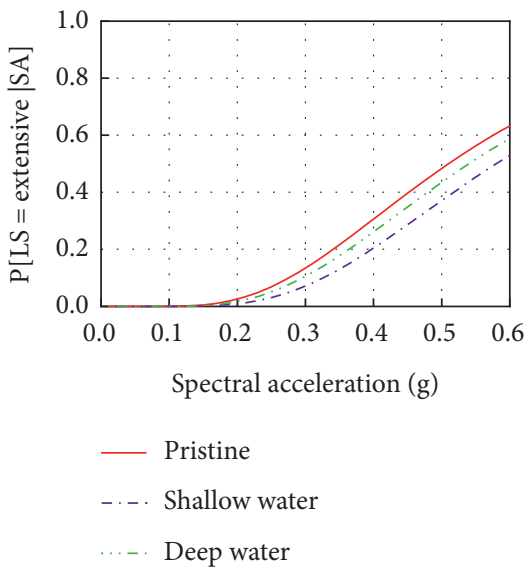

(b)

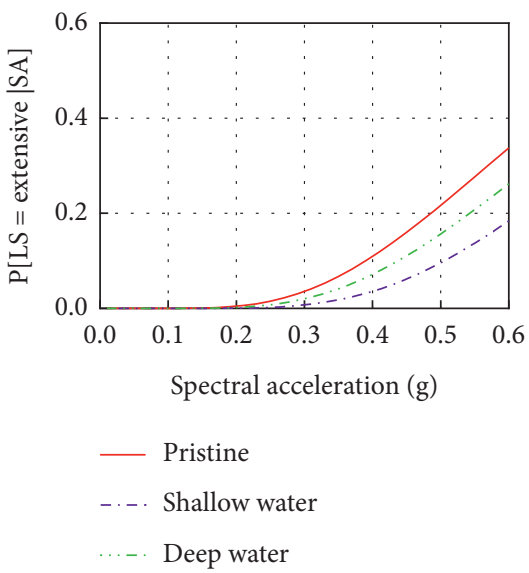

(e)

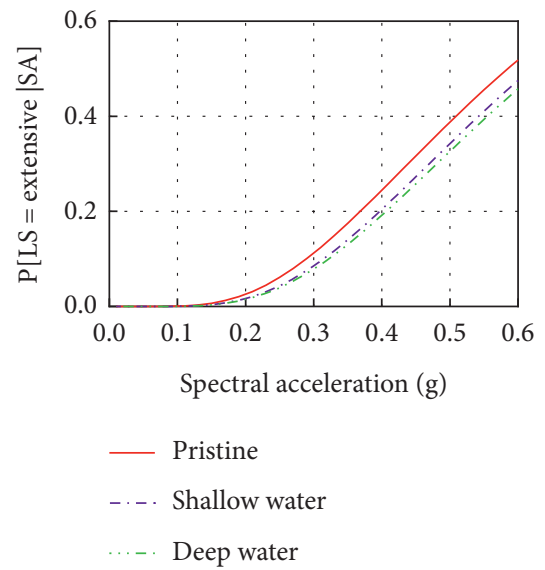

(c)

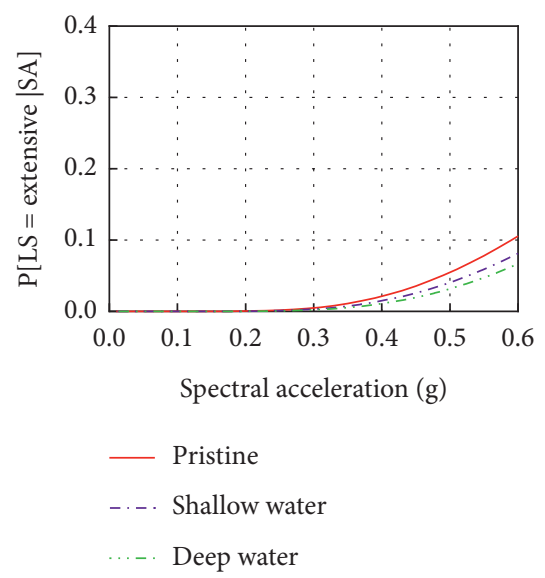

(f)

FIgURE 13: Time-dependent fragility curves of (a) shear keys at abutment, (b) shear keys at pier 1, (c) shear keys at pier 3, (d) PTFE sliding bearings at abutment, (e) rubber bearings at pier 1, and (f) rubber bearings at pier 3 under different water region.

(4) the section at high water level. In theory, the yield sequence of piers can be determined by comparing the curvature demand during earthquakes and yield curvature capacity (corresponding curvature capacity at moderate damage state), as shown in Figure 14.

Theoretically, the double-column pier can be regarded as a cantilever column in longitudinal direction. Therefore, the distribution of longitudinal curvature demand of piers before yielding can be simplified to a linear relationship (Figure 14(a)). On the contrary, the framing effects between the columns and the bents result in the distribution of curvature demand of piers in transverse direction presenting the double triangle curves before the pier yields (Figure 14(b)) [31]. On the other hand, the yield curvature 


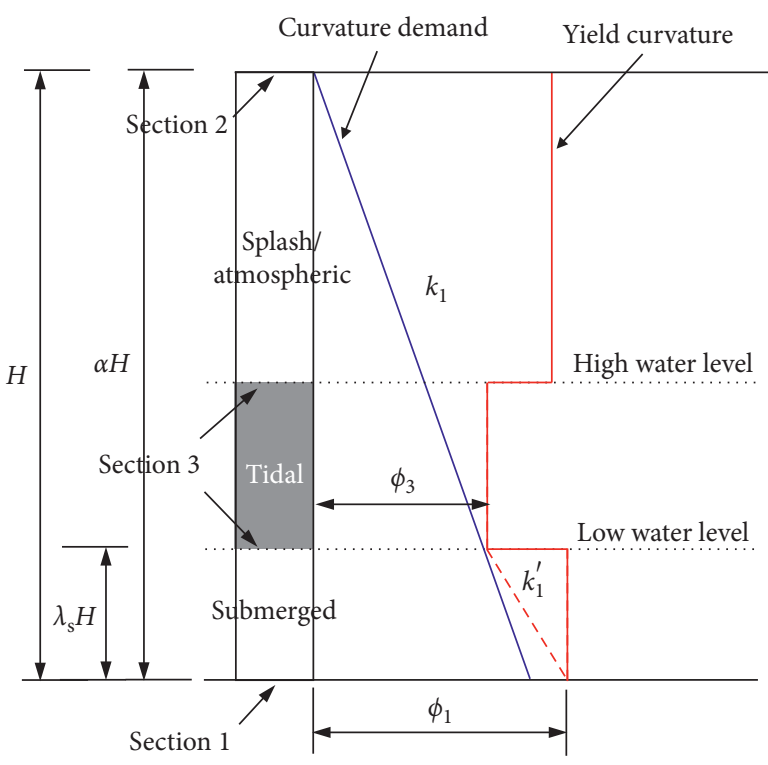

(a)

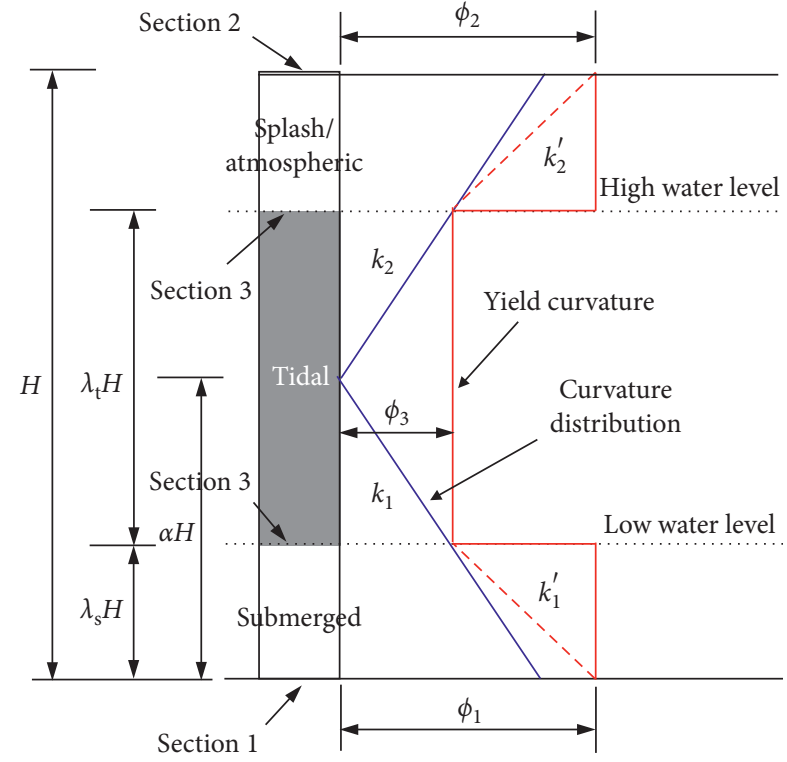

(b)

FIGURE 14: Evolution condition of yield sequence of corroded piers in (a) longitudinal direction and (b) transverse direction.

capacity of piers presents a stepped distribution due to the nonuniform degradation. By comparing the slope of curvature demand distribution and curvature capacity distribution, the evolution probability of yield sequence of piers can be described as follows:

$$
\begin{aligned}
& \begin{cases}P=P\left(k_{1}^{\prime} \leq k_{1}\right), & \text { longitudinal direction, } \\
P=P\left[\left(k_{1}^{\prime} \leq k_{1}\right) \cup\left(k_{2}^{\prime} \leq k_{2}\right)\right]=1-P\left[\left(k_{1}^{\prime}>k_{1}\right) \cap\left(k_{2}^{\prime}>k_{2}\right)\right], & \text { transverse direction, }\end{cases} \\
& k_{1}=\left(\alpha-\lambda_{s}\right) \frac{H}{\varphi_{3}}, \\
& k_{1}^{\prime}=\lambda_{s} \frac{H}{\left(\varphi_{1}-\varphi_{3}\right)} \text {. } \\
& k_{2}=\left(\lambda_{t}+\lambda_{s}-\alpha\right) \frac{H}{\varphi_{3}}, \\
& k_{2}^{\prime}=\left(1-\lambda_{s}-\lambda_{t}\right) \frac{H}{\left(\varphi_{2}-\varphi_{3}\right)},
\end{aligned}
$$

where $\alpha$ is the ratio between the distance from inflection points to the bottom of piers and the height of piers, which can be assumed to be 1 and 0.5 in longitudinal and transverse directions, respectively; $\lambda_{s}$ is the ratio between the depth of submerged zone and the height of piers; $\lambda_{t}$ is the ratio between the depth of tidal zone and the height of piers; $H$ is the height of pier; $\varphi_{1}, \varphi_{2}$, and $\varphi_{3}$ are the yield curvatures of section 1 (bottom section), section 2 (top section), and section 3 (section at low or high water level), respectively.

Thus, equation (23) can be rewritten as follows:

$$
\begin{cases}P=P\left[\alpha_{31} \leq\left(1-\lambda_{s}\right)\right], & \text { longitudinal direction, } \\ P=1-P\left\{\left[\alpha_{31}>\left(1-2 \lambda_{s}\right)\right] \cap\left[\alpha_{32}>\left(2 \lambda_{s}+2 \lambda_{t}-1\right)\right]\right\}, & \text { transverse direction, }\end{cases}
$$




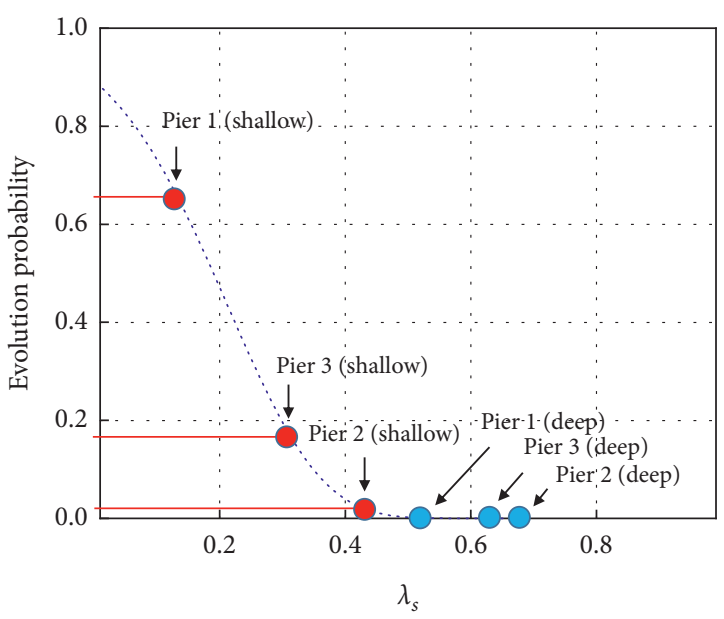

(a)

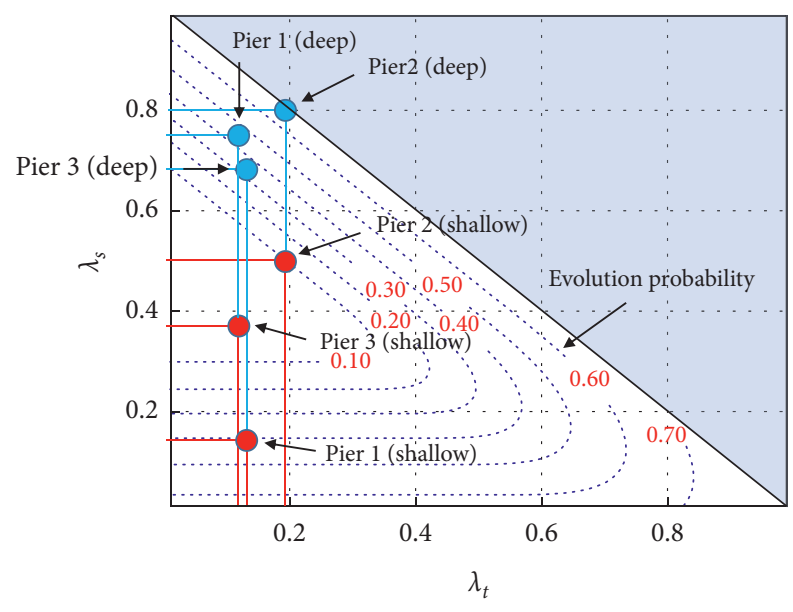

(b)

Figure 15: Effects of $\lambda_{s}$ and $\lambda_{t}$ on the evolution probabilities of yield sequence of corroded piers in (a) longitudinal direction and (b) transverse direction.

where $\alpha_{31}$ is the yield curvature ratio between sections 1 and 3; $\alpha_{32}$ is the yield curvature ratio between sections 2 and 3 .

Subsequently, the Monte Carlo simulation method is applied to obtain the evolution probability of yield sequence based on equation (26). Figure 15(a) shows the influences of $\lambda_{s}$ on the evolution probability of yield sequence of corroded piers in longitudinal direction. From the figure, it can be seen that the evolution probability of yield sequence rapidly decreases with the increase in $\lambda_{s}$. For the case study of bridge, the evolution probabilities of pier 1 in shallow water and deep water are $66.4 \%$ and $0.1 \%$, respectively. In addition, the evolution probabilities of pier 1 and pier 2 in shallow water are $66.4 \%$ and $0.3 \%$, respectively. It is indicated that the yield sequence of corroded piers in longitudinal direction is more likely to evolve in shallow water than in deep water. Moreover, the yield sequence of short pier is more likely to evolve than that of tall pier in a bridge.

On the other hand, Figure 15(b) represents the influences of $\lambda_{s}$ and $\lambda_{t}$ on the evolution probability of yield sequence of corroded piers in transverse direction. For a constant $\lambda_{t}$, the evolution probability will first decrease and then increase with the growth of $\lambda_{s}$. For example, the evolution probability of piers will reduce from $49.0 \%$ to $9.9 \%$ for $\lambda_{s}$ in the range from 0.1 to 0.3 when $\lambda_{t}$ is equal to 0.3 . Next, the evolution probability increases to $33.2 \%$ with $\lambda_{s}$ reaching 0.8 . It can be inferred that the evolution of yield sequence in transverse direction will be easy to happen in both the shallow water and the deep water. Moreover, higher $\lambda_{t}$ is more likely to cause the evolution of the yield sequence of corroded piers in transverse direction.

\section{Conclusion}

This study assessed the seismic damage of aging RC bridges subject to spatial chloride-induced corrosion in marine environments. Moreover, a method is proposed to determine the evolution probability of yield sequence of corroded piers, and the influence factors are further investigated. Generally, the following conclusions can be obtained:

(1) The corrosion level of reinforcing steels in tidal zone is the most serious, followed by the splash zone, atmospheric zone, and submerged zone. Moreover, the transverse reinforcement experiences more remarkable corrosion than the longitudinal reinforcement. The chloride-induced corrosion will significantly decrease the moment capacity and curvature ductility of piers. Meanwhile, the influence of corrosion on the initial stiffness of piers is relatively slight.

(2) The seismic damage probability will present nonlinear increase trends with the increase of time when the piers suffer spatial chloride-induced corrosion. Moreover, the corroded pier is easy to turn from low damage states to high damage states during earthquakes because of its poor ductility level. Furthermore, the nonuniform degradation along the pier direction may result in the sections at the low water level and/or high water level becoming more vulnerable than the adjacent sections, entailing the alteration of damage distribution of corroded piers or even the yield sequence of corroded piers in some cases.

(3) The spatial chloride-induced corrosion of piers will decrease the seismic response of other components, resulting in a reduction of seismic damage probability of various components. Moreover, the alteration of seismic damage distribution of piers will aggravate the variation degree of damage probability of components. It should be noted that the opposite degradation trends between piers and other components may change the most vulnerable component in the whole bridge.

(4) The evolution probabilities of yield sequence of corroded piers are dependent on the relationships 
among the height of piers and the depths of submerged zone and tidal zone. A lower ratio between the depth of submerged zone and the height of piers will increase the evolution probabilities of yield sequence of corroded piers in longitudinal and transverse directions. Moreover, the yield sequence of corroded piers in transverse direction is also more likely to evolve in a higher ratio between the depth of submerged zone and the height of piers. Meanwhile, a lower ratio between the depth of tidal zone and the height of piers will relieve the evolution of yield sequence of piers.

\section{Data Availability}

The data used to support the findings of this study are available from the corresponding author upon request.

\section{Conflicts of Interest}

The authors declare that they have no conflicts of interest.

\section{Acknowledgments}

This study was supported by the Natural Science Foundation of Jiangxi Province of China (no. 20192BAB216033), the China Postdoctoral Science Foundation (no. 2020M671972), and the National Innovation and Entrepreneurship Training Program for Undergraduate Students of China (no. 201910403021).

\section{References}

[1] D. E. Choe, P. Gardoni, D. Rosowsky, and T. Haukaas, "Probabilistic capacity models and seismic fragility estimates for RC columns subject to corrosion," Reliability Engineering \& System Safety, vol. 93, no. 3, pp. 383-393, 2008.

[2] R. Kumar, P. Gardoni, and M. Sanchez-Silva, "Effect of cumulative seismic damage and corrosion on the life-cycle cost of reinforced concrete bridges," Earthquake Engineering \& Structural Dynamics, vol. 38, no. 7, pp. 887-905, 2009.

[3] A. Alipour, B. Shafei, and M. Shinozuka, "Performance evaluation of deteriorating highway bridges located in high seismic areas," Journal of Bridge Engineering, vol. 16, no. 5, pp. 597-611, 2011.

[4] Y. Thanapol, M. Akiyama, and D. M. Frangopol, "Updating the seismic reliability of existing RC structures in a marine environment by incorporating the spatial steel corrosion distribution: application to bridge piers," Journal of Bridge Engineering, vol. 21, no. 7, Article ID 04016031, 2016.

[5] F. Cui, H. Zhang, M. Ghosn, and Y. Xu, "Seismic fragility analysis of deteriorating RC bridge substructures subject to marine chloride-induced corrosion," Engineering Structures, vol. 155, pp. 61-72, 2018.

[6] B. Panchireddi and J. Ghosh, "Cumulative vulnerability assessment of highway bridges considering corrosion deterioration and repeated earthquake events," Bulletin of Earthquake Engineering, vol. 17, no. 3, pp. 1603-1638, 2019.

[7] Y. Zhang, R. DesRoches, and I. Tien, "Impact of corrosion on risk assessment of shear-critical and short lap-spliced bridges," Engineering Structures, vol. 189, pp. 260-271, 2019.
[8] P. Crespi, M. Zucca, and M. Valente, "On the collapse evaluation of existing RC bridges exposed to corrosion under horizontal loads," Engineering Failure Analysis, vol. 116, Article ID 104727, 2020.

[9] W. Yuan, A. Guo, W. Yuan, and H. Li, "Shaking table tests of coastal bridge piers with different levels of corrosion damage caused by chloride penetration," Construction and Building Materials, vol. 173, pp. 160-171, 2018.

[10] DuraCrete, "Statistical quantification of the variables in the limit state functions," DuraCrete Inc., Salt Lake City, UT, USA, The European Union-Brite EuRam III-Contract BRPRCT95-0132-Project BE95-1347/R9, 2000.

[11] Y. C. Ou and N. D. Nguyen, "Plastic hinge length of corroded reinforced concrete beams," ACI Structural Journal, vol. 111, no. 5, pp. 1049-1058, 2014.

[12] D. V. Val and R. E. Melchers, "Reliability of deteriorating RC slab bridges," Journal of Structural Engineering, vol. 123, no. 12, pp. 1638-1644, 1997.

[13] M. G. Stewart and A. Al-Harthy, "Pitting corrosion and structural reliability of corroding RC structures: experimental data and probabilistic analysis," Reliability Engineering \& System Safety, vol. 93, no. 3, pp. 373-382, 2008.

[14] M. B. Otieno, M. G. Alexander, and H.-D. Beushausen, "Corrosion in cracked and uncracked concrete - influence of crack width, concrete quality and crack reopening," Magazine of Concrete Research, vol. 62, no. 6, pp. 393-404, 2010.

[15] C. Cao, M. M. S. Cheung, and B. Y. B. Chan, "Modelling of interaction between corrosion-induced concrete cover crack and steel corrosion rate," Corrosion Science, vol. 69, pp. 97109, 2013.

[16] K. A. T. Vu and M. G. Stewart, "Structural reliability of concrete bridges including improved chloride-induced corrosion models," Structural Safety, vol. 22, no. 4, pp. 313-333, 2000.

[17] Y. G. Du, L. A. Clark, and A. H. C. Chan, "Residual capacity of corroded reinforcing bars," Magazine of Concrete Research, vol. 57, no. 3, pp. 135-147, 2005.

[18] D. Coronelli and P. Gambarova, "Structural assessment of corroded reinforced concrete beams: modeling guidelines," Journal of Structural Engineering, vol. 130, no. 8, pp. 12141224, 2004.

[19] F. J. Vecchio and M. P. Collins, "The modified compressionfield theory for reinforced concrete elements subjected to shear," ACI Journal, vol. 83, no. 2, pp. 219-231, 1986.

[20] T. Vidal, A. Castel, and R. François, "Analyzing crack width to predict corrosion in reinforced concrete," Cement and concrete Research, vol. 34, no. 1, pp. 165-174, 2004.

[21] J. B. Mander, M. J. N. Priestley, and R. Park, "Theoretical stress-strain model for confined concrete," Journal of Structural Engineering, vol. 114, no. 8, pp. 1804-1826, 1988.

[22] L. Li, S. Hu, and L. Wang, "Seismic fragility assessment of a multi-span cable-stayed bridge with tall piers," Bulletin of Earthquake Engineering, vol. 15, no. 9, pp. 3727-3745, 2017.

[23] S. Mazzoni, F. McKenna, M. H. Scott, and G. L. Fenves, "Opensees command language manual," Pacific Earthquake Engineering Research (PEER) Center, vol. 264, 2006.

[24] N. Shome, C. A. Cornell, P. Bazzurro, and J. E. Carballo, "Earthquakes, records, and nonlinear responses," Earthquake Spectra, vol. 14, no. 3, pp. 469-500, 1998.

[25] J. E. Padgett, B. G. Nielson, and R. DesRoches, "Selection of optimal intensity measures in probabilistic seismic demand models of highway bridge portfolios," Earthquake Engineering \& Structural Dynamics, vol. 37, no. 5, pp. 711-725, 2008. 
[26] Z. Yuan, C. Fang, M. Parsaeimaram, and S. Yang, "Cyclic behavior of corroded reinforced concrete bridge piers," Journal of Bridge Engineering, vol. 22, no. 7, Article ID 04017020, 2017.

[27] A. S. Rajput and U. K. Sharma, "Corroded reinforced concrete columns under simulated seismic loading," Engineering Structures, vol. 171, pp. 453-463, 2018.

[28] H. Yalciner, S. Sensoy, and O. Eren, "Time-dependent seismic performance assessment of a single-degree-of-freedom frame subject to corrosion," Engineering Failure Analysis, vol. 19, pp. 109-122, 2012.

[29] D. Sobhani, S. Zarei, H. Savoj, and M. Shayanfar, "Investigation on corrosion effects of reinforcement on the momentcurvature diagram of reinforced concrete sections," Mapta Journal of Architecture, Urbanism and Civil Engineering (MJAUCE), vol. 1, no. 3, pp. 11-22, 2018.

[30] FEMA, Multi-hazard Loss Estimation Methodology: Earthquake Model, Department of Homeland Security, FEMA, Washington, DC, USA, 2003.

[31] Transportation Officials Subcommittee on Bridges, AASHTO Guide Specifications for LRFD Seismic Bridge Design, AASHTO, Washington, DC, USA, 2011. 